\title{
Does Seston Quality Limit the Presence of Mussels on Wellington's South Coast? \\ FlowCAM investigation of seston particle type
}

\section{Rata Pryor Rodgers}




\section{Acknowledgments}

I am most thankful to my supervisor Professor Jonathan Gardner, who has continually provided me with advice and guidance along the way. There are number of other people I need to thank who have helped throughout this research process. I am very thankful to John van der Sman at VUCEL who every week collected water samples for me and provided me with technical advice during my experiments. I would also like to thank Matt Pinkerton from NIWA who provided me with very informative satellite data, I really appreciate the time he took to process and explain the data to me.

There are a number of people from Cawthron Institute I need to thank. To Kevin Heasman for hosting me during my experiments in Nelson. To Ellie Watts and Wayne Hiini for helping me set up the experiments and keep them running. To Norman Ragg and Irrintzi Ibarrola who provided me with very helpful tips and advice along the way. And a big thank you to Catherine Anderson who answered every question I had while finding my way around the aquaculture centre.

For financial support I am grateful for the Tu Horomata scholarship and to Ngāi Tahu Kā Pūtea Grants. I would like to also thank my employers lan and Sharon Johnston, who have been so flexible with me taking off to Nelson and have provided me with an endless supply of coffee. I would like to extend a huge thank you to my family. To my mum, Faye, for installing a passion for learning in me and encouraging me to pursue my studies. And for spending hours proof reading! To my dad, Bruce, for establishing a love of the sea within in and for always being up for a 'quick' dive. To Lily and Brydie for always being up for a yarn about mussels and being a continual source of support for me. 


\section{Abstract}

Temperate rocky shores around the world are characterised by so-called 'universal' zonation. An interesting exception to this rule can be seen along the shores of Wellington's South Coast where there is a virtual absence of mussels and poorly developed rocky shore intertidal community. Yet just kilometres away in Wellington Harbour there is a fully developed intertidal community, including extensive multi-species mussel beds. This thesis aims to determine if the quality of seston is limiting the presence of mussels on Wellington's South Coast. We now have the technology to see what types of particles the mussels are selecting in low and high quality seston conditions using a FlowCAM that allows identification of particle types and their physical properties.

This study compared environmental data for Wellington Harbour (seston-rich) and the South Coast (seston-poor). These data included chlorophyll $a$, turbidity and suspended sediment concentrations and were collected by CTD and satellite remote sensing. Mussel feeding experiments took place under a high and low quality diet during summer, autumn and winter using Perna canaliculus and Mytilus galloprovincialis. The physiological responses recorded were clearance rate, absorption efficiency and net energy balance for individual mussels. Environmental variables recorded were total particulate matter, particulate organic matter and percent organic matter. Water samples were collected during the feeding experiments and processed using the FlowCAM. By comparing the control chambers to chambers that had mussels feeding in them it was possible to see what particles the mussels were selecting.

The environmental variables revealed that Wellington Harbour had a much higher quality seston whereas in Cook Strait the seston quality was too low for mussels to be able to inhabit, as the chlorophyll $a$ concentrations did not reach the required levels for mussel growth. Perna canaliculus and Mytilus galloprovincialis both showed physiological responses that would allow them to grow in Cook Strait waters, both species had positive absorption efficiencies and net energy balances. These responses were greater in the high quality diet in the enriched pond water in Nelson during summer and winter. The FlowCAM analysis revealed an interspecific difference in preferential particle selection, which varied as a function of site and season. With more particles being preferentially selected in the high quality diet compared to 
when the mussels were feeding on Cook Strait seawater. This new information of particle selection helps to determine why mussels are absent from Wellington's South Coast and contributes to the extensive information on mussel feeding. 


\section{Table of Contents}

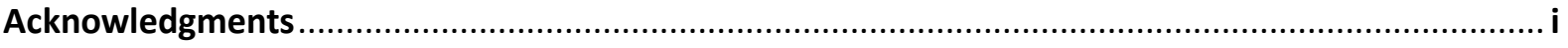

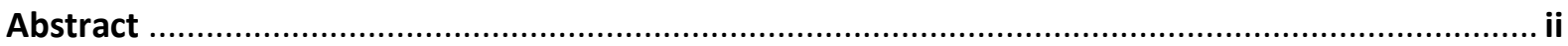

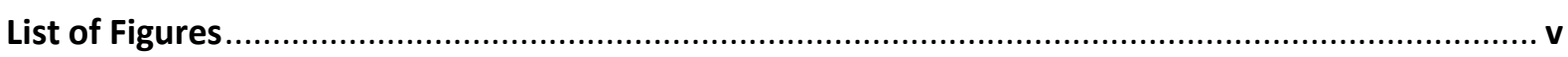

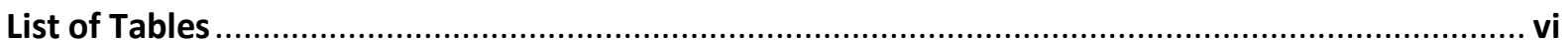

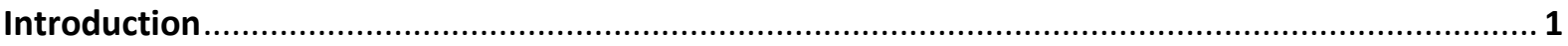

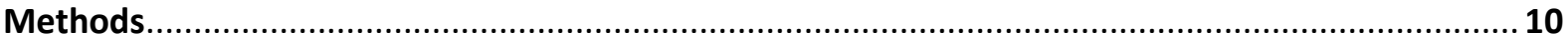

1. Environmental characteristics of Wellington Harbour and Cook Strait..................................... 10

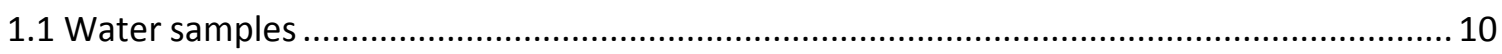

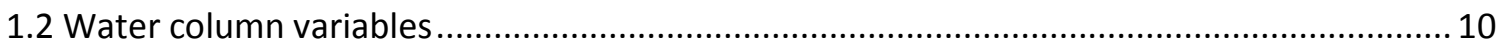

1.3 Satellite data of chlorophyll $a$ and suspended matter concentrations ................................. 10

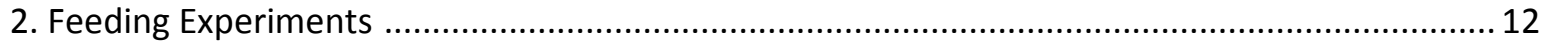

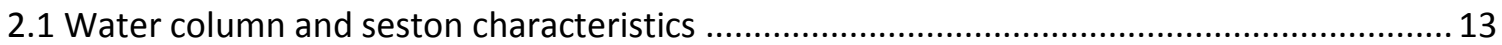

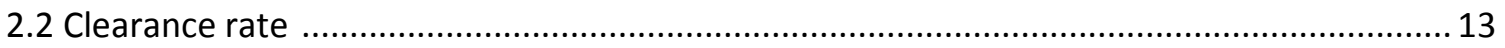

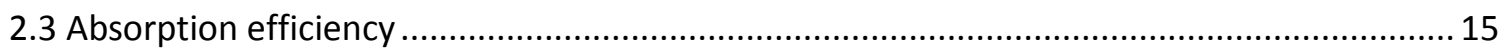

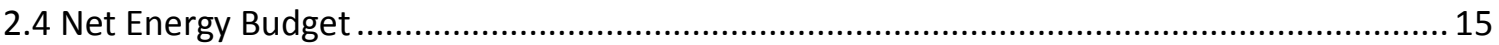

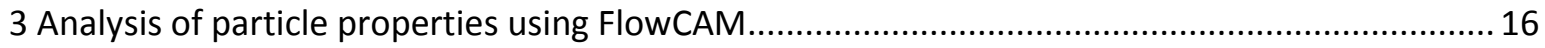

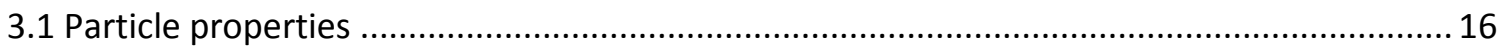

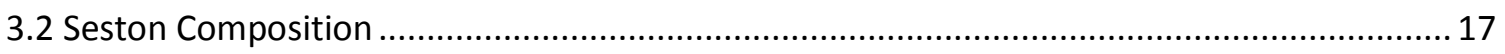

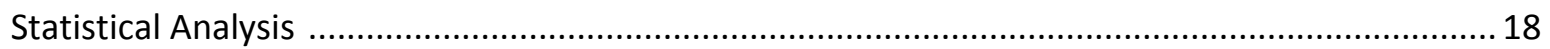

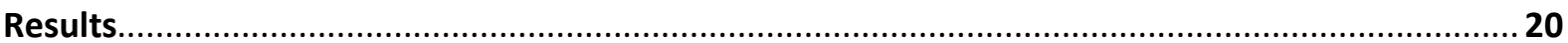

1. Environmental characteristics of Wellington Harbour and Cook Strait.......................................2 20

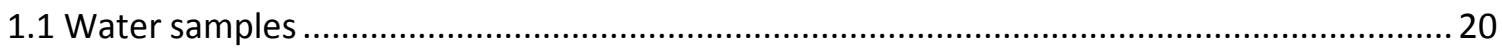

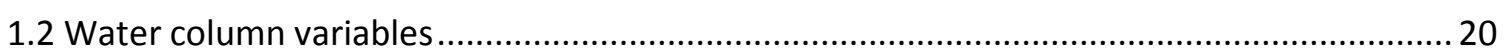

1.3 Satellite data of chlorophyll $a$ and suspended matter concentrations .................................. 23

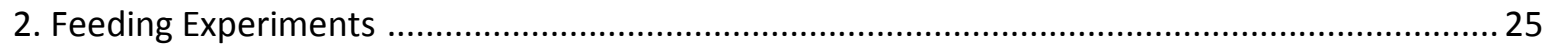

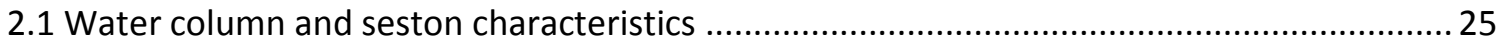

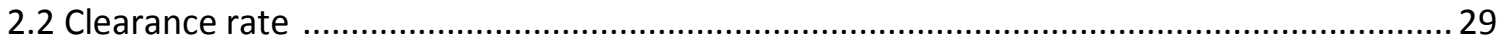

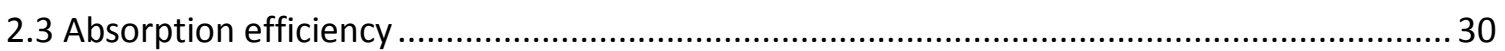

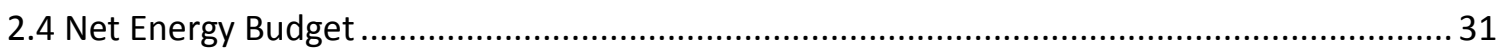

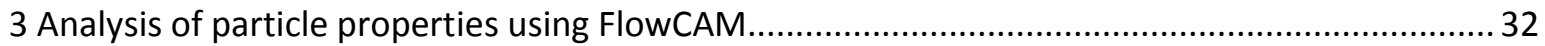

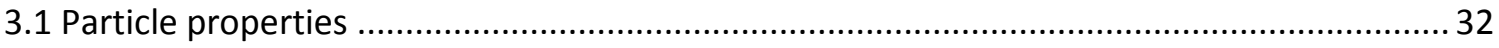

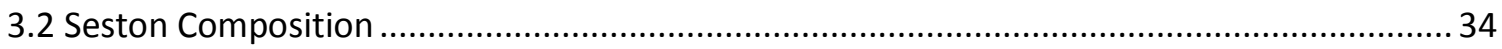

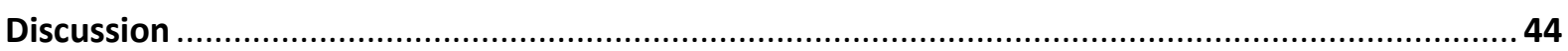

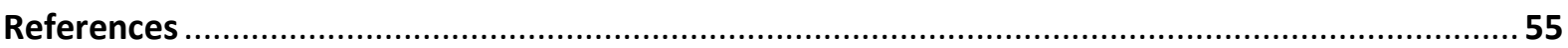

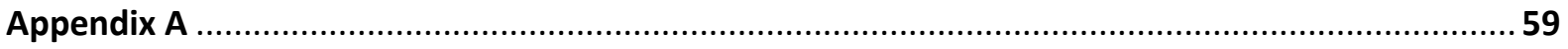

Appendix B 


\section{List of Figures}

Figure 1. Map of locations of sites for satellite data for total suspended sediment and chlorophyll a. Adapted from Helson et al. (2007).

Figure 2. . Map showing locations of mussel feeding experiments. Cawthron Aquaculture Park is located on Tasman Bay, Nelson. VUCEL is located in Island Bay (Cook Strait).

Figure 3. Mean $( \pm S D)$ of temperature, turbidity, chlorophyll $a$ and salinity in Island Bay, Cook Strait, light grey) and Matiu/Somes Island, Wellington Harbour (black). August to December is data from 2005, January to May is 2006 data. No available for salinity in Cook Strait in May due to inaccuracies in recorded values.

Figure 4. Mean monthly $( \pm \mathrm{SD})$ total suspended sediment $\left(\mathrm{mg} \mathrm{l}^{-1}\right)$ and Chlorophyll $a\left(\mu \mathrm{gl}^{-1}\right)$ at Matiu/Somes Island (light blue), Scorching Bay (dark blue), Cook Strait (dark green) and Island Bay (light green). Monthly averages are based on data from 2002 - 2014.

Figure 5. Mean ( \pm SD) of TPM $\left(\mathrm{mg} \mathrm{l}^{-1}\right)$, POM $\left(\mathrm{mg} \mathrm{l}^{-1}\right)$, PCOM (\%) and particle count (number of particles $\mathrm{ml}^{-1}$ ) in summer, autumn and winter. Island Bay is shown in light grey and Nelson is shown in black.

Figure 6. Standardised clearance rate (CRs) in $~^{-1} \mathrm{~h}^{-1}$ (mean $\pm \mathrm{SD}$ ) of $P$. canaliculus and $M$. galloprovincialis during three seasons at Island Bay and Nelson. Light blue $=M$. galloprovincialis in Island Bay, light green $=P$. canaliculus in Island Bay, dark blue $=M$. galloprovincialis in Nelson and dark green $=P$. canaliculus in Nelson .

Figure 7. Absorption efficiency (mean $\pm \mathrm{SD}$ ) of $P$. canaliculus and $M$. galloprovincialis during three seasons at Island Bay and Nelson. Light blue $=M$. galloprovincialis in Island Bay, light green $=P$. canaliculus in Island Bay, dark blue $=M$. galloprovincialis in Nelson and dark green $=P$. canaliculus in Nelson.

Figure 8. Net Energy Budget in $\mathrm{J} \mathrm{g}^{-1} \mathrm{~h}^{-1}$ (mean $\pm \mathrm{SD}$ ) of $P$. canaliculus and $M$. galloprovincialis during three seasons at Island Bay and Nelson. Light blue $=M$. galloprovincialis in Island Bay, light green $=P$. canaliculus in Island Bay, dark blue $=M$. galloprovincialis in Nelson and dark green $=P$. canaliculus in Nelson.

Figure 9. The number of particles per $\mathrm{ml}$ (forth-root transformed) $\pm S D$, of particles types recorded in Island Bay during autumn. The blue bars are $M$. galloprovincialis, the green are $P$. canaliculus and the control is shown in black

Figure 10. The number of particles per $\mathrm{ml}$ (forth-root transformed) $\pm \mathrm{SD}$, of particles types recorded in Island Bay during winter. The blue bars are M. galloprovincialis, the green are P. canaliculus and the control is shown in black

Figure 11. The number of particles per $\mathrm{ml}$ (forth-root transformed) $\pm S D$, of particles types recorded in Nelson during autumn. The blue bars are M. galloprovincialis, the green are $P$. canaliculus and the control is shown in black

Figure 12. The number of particles per $\mathrm{ml}$ (forth-root transformed) $\pm S D$, of particles types recorded in Nelson during winter. The blue bars are M. galloprovincialis, the green are $P$. canaliculus and the control is shown in black 


\section{List of Tables}

Table 1. Mean $( \pm S D)$ temperature, turbidity, chlorophyll $a$ and salinity for Island Bay (Cook Strait) and Matiu/Somes Island (Wellington Harbour)

Table 2. Mean $( \pm S D$ ) particle count (particles per $\mathrm{ml})$, total particulate matter $\mathrm{mg} \mathrm{l}^{-1}(\mathrm{TPM})$, particulate organic matter $\mathrm{mg} \mathrm{l}^{-1}$ (POM) and percent organic matter (PCOM) at Island Bay (Cook Strait) and Nelson (Tasman Bay) during summer, autumn and winter..

Table 3. Mean $( \pm S D)$ temperature $\left({ }^{\circ} \mathrm{C}\right)$, turbidity (NTU), chlorophyll $a\left(\mu \mathrm{g} \mathrm{I}^{-1}\right)$ and salinity (PSU) at Island Bay (Cook Strait) and Nelson (Tasman Bay) during summer, autumn and winter.

Table 4. Mean ( \pm SD) standardised clearance rates in $\mathrm{I} \mathrm{g}^{-1} \mathrm{~h}^{-1}(\mathrm{CRs})$, absorption efficiencies $(A E)$ and net energy budget in $\mathrm{J} \mathrm{g}^{-1} \mathrm{~h}^{-1}$ (NEB) at Island Bay and Nelson during summer, autumn and winter for $M$. galloprovincialis and $P$. canaliculus

Table 5. Results from PERMANOVA differences in each particle type (particles $\mathrm{ml}^{-1}$ ) between the control chamber and the experimental chambers of $M$. galloprovincialis or $P$. canaliculus during autumn in Island Bay. Bold denotes significant differences at $\alpha=0.10$ .35

Table 6. Results from PERMANOVA differences in each particle type (particles $\mathrm{ml}^{-1}$ ) between the control chamber and the experimental chambers of $M$. galloprovincialis or $P$. canaliculus during winter in Island Bay. Bold denotes significant differences at $\alpha=0.10$.

Table 7. Results from PERMANOVA differences in each particle type (particles $\mathrm{ml}^{-1}$ ) between the control chamber and the experimental chambers of $M$. galloprovincialis or $P$. canaliculus during autumn in Nelson. Bold denotes significant differences at $\alpha=0.10$

Table 8. Results from PERMANOVA differences in each particle type (particles $\mathrm{ml}^{-1}$ ) between the control chamber and the experimental chambers of $M$. galloprovincialis or $P$. canaliculus during winter at Nelson. Bold denotes significant differences at $\alpha=0.10$.

Appendix A1. Mean ( $\pm \mathrm{SD}$ ) chlorophyll a concentrations $\mu \mathrm{g}^{-1}$. Monthly averages are based on data from $2002-2014$.

Appendix A2. Mean ( $\pm \mathrm{SD}$ ) total suspended sediment $\mathrm{mg}^{-1}$. Monthly averages are based on data from $2002-2014$

Appendix B1. Average particle properties $( \pm S D)$ for all experiments recorded in the outflow of M. galloprovincialis, P. canaliculus and the control chambers.

Appendix B2. Description of the particle properties used in this study. Descriptions are from the FlowCAM manual (FlowCAM 2011)

Appendix B3. Average particle properties $( \pm S D)$ for all experiments recorded in the outflow of M. galloprovincialis, P. canaliculus and the control chambers.

Appendix B4. Particle types with images recorded in the FlowCAM library, table does not include 2 - $5 \mu \mathrm{m}$ ESD unidentifiable particles or $>5 \mu \mathrm{m}$ ESD unidentifiable particles. 


\section{Introduction}

Temperate rocky shores are characterised by 'universal' zonation (Stephenson and Stephenson 1949), a pattern of species of similar functional group creating non-repeating bands within the intertidal region. This community composition is common in most temperate regions around the world. An interesting exception to the general rule of zonation can be seen on Wellington's south coast, the Cook Strait, where there is a virtual absence of mussels on the rocky shore and generally an under-developed rocky shore community. What makes this situation even more interesting is that just a few kilometres away in Wellington Harbour there is a well-developed intertidal community, with an abundance of mussels of four species (Gardner 2000, 2002). The reasons why there is an absence of mussels on the Cook Strait have been studied from a number of different angles including larval abundance and recruitment (Helson and Gardner 2004, Demello and Phillips 2011), wave exposure (Tam 2012), predation and competition (Phillips and Hutchison 2008, Tam 2012), but the aspect that has been most well studied and is currently explaining most of the variation seen is food limitation (Gardner 2000, Gardner and Thompson 2001, Gardner 2002, Helson et al. 2007, Gardner 2013).

Rocky intertidal habitats are some of the most studied and best understood habitats in the marine environment (Bird et al. 2013). Stephenson and Stephenson (1949) described the universal pattern of zonation after studying rocky intertidal communities in temperate regions worldwide. They found that similar functional groups of organisms formed bands, ranging from lichens, then littorinid snails in the upper intertidal range, barnacles, mussels in the mid-intertidal zone and macroalgae in the lower regions. The common structure and function of the intertidal community and species distribution is determined by a combination of biological and physical processes. The biological processes such as predation and competition for resources limit the lower distribution of species, while the physical stressors such as temperature, wave exposure and desiccation define the upper limits (Connell 1961, Paine 1966, Underwood 2000) and the combination of both defines the realised distribution of species living on the rocky shores (Bird et al. 2013).

Although the universal rule of zonation stands for many rocky intertidal communities the Cook Strait shores on Wellington's South Coast do not fit this pattern. There is an almost 
complete absence of mussels in the mid-intertidal zone and a poorly developed intertidal community. Yet just kilometres away in Wellington Harbour there is a fully developed intertidal community which includes extensive multi-species mussel beds. Cook Strait is the body of water that separates the North Island from the South Island of New Zealand. The D'Urville Current brings oceanic water in a northwest direction from the Tasman Sea (Bowman et al. 1983). Carbon to nitrogen (C:N) ratios indicate that the seston present in the Cook Strait is predominantly new production, with very little detritus contribution (Gardner and Thompson 2001). Wellington Harbour is a large, semi-enclosed body of water. The Hutt River flows into the northern end providing nutrients and particulate-rich riparian water (Bowman et al. 1983, Gardner 2000, 2013).

Although there is sufficient space in the form of bare rock for mussels to inhabit, there is a general absence of all mussel species along Wellington's South Coast, some parts of the Marlborough Sounds in the South Island, along the southern coasts of Wairarapa and Cape Palliser, and north to Paekakariki (Gardner 2008). Occasionally small patches of the little black mussel Limnoperna pulex (Gardner 2008) or the blue mussel Mytilus galloprovincialis are found in low abundances (Tam 2012) and other filter feeders such as the barnacle Chamaesipho columna are infrequently found (Demello and Phillips 2011). At the entrance to Wellington Harbour a transition of less than a kilometre occurs from the absence of mussels to abundant, dense mussel beds (Helson 2001). In Wellington Harbour four species of mussels co-exist. In the upper regions of the intertidal zone the little black mussel Limnoperna pulex, in the mid regions the ribbed mussel Aulacomya maoriana, the blue mussel Mytilus galloprovincialis, and in the lower intertidal the green mussel Perna canaliculus. A. maoriana and P. canaliculus are endemic to New Zealand waters, and $P$. canaliculus is a valuable recreational and aquaculture species.

Mussels are important species on intertidal rocky shores as they play a key role in the flow of energy and matter in to the intertidal ecosystem (Strohmeier et al. 2012). Mussels are sessile suspension feeders that filter large volumes of water to capture the seston (phytoplankton and detrital material). Benthic suspension feeders are considered some of the most efficient communities at extracting resources from the oceans (Gili and Coma 1998). Because mussels filter such a large amount of seston out of the water column they are an important link in pelagic-benthic coupling (Ward and Shumway 2004). Dense mussel beds 
have been shown to reduce seston concentrations, particle composition and the plankton population dynamics in the water flowing over the beds (Maar et al. 2007, Strohmeier et al. 2012). The reduction in seston can also reduce the amount of suspended organic carbon and the turbidity of the water which can have flow-on effects of increasing light availability (Ward and Shumway 2004). Although mussels reduce phytoplankton populations by grazing they can also enhance production by recycling inorganic nutrients back into the water column (Ogilvie et al. 2000). By consuming phytoplankton mussels are connecting large scale process to the intertidal community as they then become a food source for whelks, crabs, starfish, fish and birds (Bracken et al. 2012). In addition, mussels are ecosystem engineers as they provide shelter and space for other species to live in (Arribas et al. 2014). They are strong competitors for space and can form large dense beds. These factors separately or combined show that mussels play an important part in the structure and function of the rocky shore intertidal community.

Mussels are broadcast spawners, with external fertilisation and a plankton larval stage of 4 to 6 weeks (Helson and Gardner 2004). A number of studies have investigated recruitment and settlement of mussel larvae as a factor limiting the presence of mussels. Helson and Gardner (2004) found mussels were present in the plankton tows in the Cook Strait during the whole study period which were collected monthly from September 1998 to February 2000, although far more abundant in Wellington Harbour. The newly recruited larvae were also measured and again it was found that recruitment occurs on the Cook Strait in every monthly sample but they were less abundant than in Wellington Harbour (Helson and Gardner 2004). This is supported by the findings of Phillips and Hutchison (2008).

The recruitment density of mussels was found to be similar to the adult population in the type of species and the abundance (Demello and Phillips 2011). Thousands of larvae were collected, predominantly in autumn and winter in Wellington Harbour, while in the Cook Strait over a two year period only 43 recruits were collected (Demello and Phillips 2011). Phillips et al. (2008) identified the settlers using molecular markers, finding that $M$. galloprovincialis was the most common settler. Interestingly, the little black mussel L. pulex had a higher abundance of recruits on the Cook Strait than in Wellington Harbour. This finding is supported by the settlement in exclusion plots on the Cook Strait where only L. pulex had settled, although in very low densities (Phillips and Hutchison 2008). Even though mussel 
larvae and recruitment were found to have a lower abundance within the Cook Strait compared to Wellington Harbour they were present in both. This suggests that recruitment and settlement of larvae is not the dominant factor causing the lack of mussels on the South Coast.

Due to the exposed nature of Cook Strait (wave heights can often reach $10 \mathrm{~m}$ and have been officially recorded at $14 \mathrm{~m}$ on several occasions by NIWA), wave exposure has been proposed to limit either the ability of mussel larvae to successfully recruit or for the adult populations to be able to withstand the exposed nature of this coastline. But other invertebrates successfully settle along this coast line (Helson and Gardner 2007), and there are a number of sheltered areas that are uninhabited by mussels (Gardner 2008). In some regions, such as the South African southern coast, wave exposure actually benefits mussel populations as it increases the availability of food resulting in a higher growth rate of the local brown mussel Perna perna. More exposed shores have been found to have a higher recruitment rate as more larvae are transported to these areas (McQuaid and Lindsay 2000, 2007). Tam (2012) studied the impact of wave exposure on mussels in Cook Strait, and found that they were unlikely to be limited by the force of the waves as there was enough suitable habitat in wave exposed areas. The rate of survival and condition of the mussels was lower in the Cook Strait but this was more likely due to food availability than wave force (Tam 2012). There is therefore no evidence in support of the idea that wave exposure alone is the factor influencing mussel distributions in central New Zealand such as Cook Strait.

Predation and competition are strong biological factors that influence the distribution of species on rocky intertidal shores (Connell 1972, Menge and Sutherland 1987). On typical rocky shore communities, space is often a limiting factor with both inter- and intra-specific competition occurring. On the Cook Strait, space availability is not a limiting factor as there is a large abundance of bare rock that is available for settlement in the upper and mid intertidal zones (Helson et al. 2007).

Predators in intertidal communities can limit species distribution (Menge 2000), but there is a lack of predatory species on the Cook Strait (Tam 2012). With the lack of predators it would be expected that mussel populations would increase as they did in Anawhata, Auckland, when the predatory starfish was removed (Paine 1971). This removal caused a dramatic increase on the population of $P$. canaliculus (Paine 1971). There is a lack of the 
mussels' main predators in the Cook Strait (Gardner 2008). Whelks have been found to predate on mussels within the harbour but the whelkpopulation is not large enough to be the cause of mussel absence from the Cook Strait (Tam 2012).

There are a number of studies that show the absence of mussels on the Cook Strait is due to, at least partially, the limited food supply available to the mussels (Gardner 2000, Gardner and Thompson 2001, Helson and Gardner 2007, Gardner 2013). Mussels are sessile suspension feeders, which actively filter seston out of the water column. Seston is composed of organic particles such as plankton, detritus and microorganisms (Ward and Shumway 2004). A large component is inorganic particles such as silt, clay and sand which have no nutritional value (Safi et al. 2007) but may be processed by mussels for attached microbiota (Riisgård et al. 2013). Seston ranges in size from $<1 \mu \mathrm{m}$ to $>1000 \mu \mathrm{m}$ (Riisgård et al. 2013). The major nutritional source of the seston for mussels comes from the phytoplankton. Seston quality and quantity vary spatially and temporally due to a number of environmental influences. Current and water column mixing are important factors in determining the availability of seston to mussel beds (Riisgård et al. 2013). There are strong seasonal changes due to the growth and depletion of phytoplankton which is controlled by light and nutrient availability, and predator grazing. The macroalgae community in the sublittoral zone can also affect the quality of seston available to mussel beds as the species present determine the nutritional value of the detrital contribution.

There is a significant difference between Wellington Harbour and Cook Strait in the quality and the quantity of seston, with the Cook Strait having a lower quality of seston which has been shown in a number of studies. Gardner (2000) found that Wellington Harbour was typical compared to other temperate coastal waters, but Cook Strait was lower than normal in POM (particulate organic matter) and PCOM (percent organic matter). Gardner and Thompson (2001) recorded the ambient PCOM levels to be lower than $25 \%$ in the Cook Strait, a value which is low for temperate water. Helson et al. (2007) conducted an 18 month study investigating eight water column characteristics at multiple sites within Wellington Harbour and Cook Strait. PCOM and chlorophyll $a$ were higher at the Wellington Harbour sites and decreased with distance from the harbour. Most recently Gardner (2013), found the chlorophyll $a$ and turbidity to be higher in Wellington Harbour compared to Cook Strait by ten and three fold, respectively. 
The food and nutrient availability of the seston has an effect on the physiology of mussels (Dahlhoff and Menge 1996). Because mussels are sessile their energetics and growth rates are determined by what is naturally available to them in the surrounding water column. The quantity and quality of available seston is variable, and mussels feeding behaviour responses vary with it (Bayne et al. 1987, Bayne et al. 1993). Chlorophyll $a$ is used as an indicator of the net phytoplankton biomass of the seston, and is correlated to mussel condition (Zeldis et al. 2004) but the relationship is variable and other factors rather than just the biomass of phytoplankton present are important in explaining mussel growth and condition (Safi and Hayden 2010). More recent research has been investigating what variables other than just the organic component of the seston defines quality (Safi and Hayden 2010, Strohmeier et al. 2012). These variables include, but are not limited to, the size structure of the phytoplankton available, chemical composition and texture of particles, and the phytoplankton species composition (Safi and Hayden 2010, Strohmeier et al. 2012).

The response of mussels to the natural seston conditions in the Cook Strait has also been studied. Gardner (2000) studied three species of mussels, Aulacomya maoriana, Mytilus galloprovincialis and Perna canaliculus, and for all species found a higher Scope for Growth (SFG) in Wellington Harbour compared to the low or negative values recorded in the Cook Strait. The SFG is the energy available for growth after routine metabolic costs have been met and is determined by the clearance rate, absorption efficiency and seston components as well as the costs of respiration. The Gardner and Thompson (2001) study of $P$. canaliculus also found negative SFG values at Island Bay (Cook Strait) in summer. Transplant experiments which moved mussels to Wellington Harbour and to the Cook Strait have resulted in lower body condition of mussels located at Cook Strait than the mussels transplanted to Wellington Harbour (Helson et al. 2007, Gardner 2013). Gardner (2013) found a slower shell growth in mussels transplanted to the Cook Strait and a higher mortality rate. The results of all these studies suggest that food availability differences between Wellington Harbour and Cook Strait contribute to the presence and absence of mussels at these sites, respectively.

As well as varying biological responses with varying seston availability, bivalves such as mussels have the ability to preferentially select or reject matter out of the seston (Ren et al. 2006). It was first suggested that mussels could actively select or reject particles nearly a hundred years ago by Allen (1921). It is now well established that mussels can preferentially 
select phytoplankton for ingestion (Ward and Shumway 2004, Safi and Hayden 2010). There are a number of processes involved in mussel feeding. Mussels use cilia on their ctenidia to remove particles from the water column. The particles are then caught on the frontal surface of the ctenidial filaments and transported to the ventral groove. Once in the ventral groove the particles are transported to the labial palps where food particles are separated from unwanted particles to the mouth. Unwanted particles are bundled in mucus and removed as pseudofaeces (Ward et al. 1998, Ward and Shumway 2004, Safi and Hayden 2010). By actively selecting certain particles and rejecting certain other ones, mussels are able to optimise the energy acquisition from the water column (Ward and Shumway 2004).

There are at least three processes involved in selection of particles as described by Shumway et al. (1985). The first is preferential selection on the ctenidia, the second is preingestive selection on the labial palps, and thirdly there is post-selective selection and how effectively the particles are absorbed in the gut. The particles are selected based on a number of factors including morphology, particle shape, motility, density, toxicity, stickiness and nutritional content (Ward and Shumway 2004, Safi and Hayden 2010, Riisgård et al. 2011).

The sorting and selection of particles is an important component of mussel feeding behaviour and energetics (Ward and Shumway 2004). By selecting particles mussels (and other bivalves) can optimise the energy acquired and enhance the quality of the food processed (Ward and Shumway 2004). It reduces the energy required by the organism to feed as it means they do not have to process a large amount of low quality, nutritionally poor or inorganic particles (Ward and Shumway 2004). It has also been suggested that they can reduce the amount of toxic particles absorbed (Ward and Shumway 2004). Because mussel growth is sensitive to the changes in food supply and they have the ability to select or reject particles, the species composition of phytoplankton has the potential to affect the different mussel species energetics (Ren and Ross 2005). In previous studies it has been found that Mytilus edulis digestion efficiency varied with different types of phytoplankton species (Wang and Fisher 1996) and that Mytilus galloprovincialis selects dinoflagellates over diatoms, and the genus Dinophysis over other dinoflagellates as they are easier to digest (Sidari et al. 1998). Ren et al. (2006) provided nine different phytoplankton species which included diatoms, dinoflagellates and flagellates to Perna canaliculus and found that assimilation efficiencies differed as a function of phytoplankton species. 
Because mussels have an important top-down role by grazing on phytoplankton, selective grazing could therefore impact the species composition of phytoplankton. For example, Ogilvie et al. (2000) found flagellates in the size range 5-20 $\mu \mathrm{m}$ declined around mussel farms in Beatrix Bay, Marlborough Sounds, and suggested this was due to heavy grazing by mussels. It is important to understand what particles mussels are preferentially removing from the water column and how this affects the phytoplankton community composition (James et al. 2001). A separate study in the Marlborough Sounds found a high variation in phytoplankton species composition (Safi and Gibbs 2003). The composition of plankton species can vary greatly over different season. A study by Mackenzie et al. (1986) found that during spring microflagellates dominated the composition while in autumn diatoms were the most dominant group.

The Cook Strait does not fit the pattern of universal zonation. It has been established that mussels are absent on the Cook Strait, at least partially, due to food limitations and which results in negative energy budgets. What is unknown is what the seston is composed of, and if it is this composition of the wrong types of food that is making the Cook Strait uninhabitable for mussels.

In this study the Flow Cytometer And Microscope (FlowCAM) will be used to analyse the type of particle mussels are preferentially selecting. The FlowCAM combines microscopy and flow cytometry (Sieracki et al. 1998) and captures images of particles from a water sample that is pumped through a flow cell (glass chamber), digitalises the images and stores the images in a spread sheet and records the each particles properties (Álvarez et al. 2013). The FlowCAM has been used to provide detailed information on the size, abundance and phytoplankton species composition in a number of studies (Zarauz et al. 2009, Álvarez et al. 2011, Álvarez et al. 2013, García-Muñoz et al. 2013).

The purpose of this thesis is:

- To study the differences in water column characteristics for Wellington Harbour and Cook Strait, and to determine the seston quantity and quality using yearly data from CTD and satellite information.

- To identify how P. canaliculus and M. galloprovincialis physiologically respond when fed naturally occurring seston at Island Bay (Cook Strait), which has been 
previously established to be of low quality (Gardner 2000, Helson et al. 2007, Gardner 2008, 2013). Compared to the responses when fed a higher quality diet from the seawater ponds at Cawthron Aquaculture Park, Nelson, and to identity how this varies through summer, autumn and winter.

- To use the FlowCAM for the first time to determine the seston composition of the Cook Strait and compare the composition to the seawater ponds at Cawthron Aquaculture Park. The FlowCAM will also be used to investigate which particles $P$. canaliculus and M. galloprovincialis are selecting or rejecting and how this differs between the two locations in autumn and winter.

It is hypothesised that low quality seston availability in Cook Strait is limiting the ability of mussels to inhabit those areas due to a lack of food. It is thought that the environmental variables will show a greater quality of seston in Wellington Harbour when compared to Cook Strait which will display low quality seston characteristics. That the feeding experiments will results in a low or negative energy gain for both mussel species when supplied with Cook Strait water. It is also hypothesised that the FlowCAM analysis will reveal that when mussels are fed with Cook Strait water there will be less favourable particle types to preferentially select, compared to when they are fed on a higher quality water supply where the mussels will be able to select a wider range of 'favourable' particles. This study will provide further insight into the food limitations occurring on the Cook Strait for mussels. And for the first time enable us to identify is the overall particulate food is limited or if the seston composition is inadequate and composed of unsuitable particles for mussels. 


\section{Methods}

\section{Environmental characteristics of Wellington Harbour and Cook Strait}

The water column-based environmental characteristics were compared for Wellington Harbour, where there are dense mussel beds composed of four species, and the Cook Strait where there is an almost complete absence of mussels.

\subsection{Water samples}

Water samples were collected weekly from July 2013 until December 2014. Water was collected from Lambton Harbour, within Wellington Harbour and outside the Victoria University Coastal Ecology Lab (VUCEL) in Island Bay which is situated on Cook Strait. Samples were collected from a depth of $30 \mathrm{~cm}$ from the shore. Three $45 \mathrm{ml}$ water samples were collected from each site each week. Three $\mathrm{ml}$ of $1 \%$ Lugol's lodine was added to preserve the water samples and all samples were stored in dark cool places until analysis.

\subsection{Water column variables}

CTD data were supplied by Jonathan Gardner. Richard Brancker CTD (conductivity, temperature, depth) sondes (XR 420) with integrated SeaPoint fluorometer and turbidimeter were set up, one in Wellington Harbour at Matiu/Somes Island (situated in the middle of the harbour), and one in the 60,000 I seawater holding tank at VUCEL in Island Bay, Cook Strait. The water column variables recorded were temperature $\left({ }^{\circ} \mathrm{C}\right)$, salinity (PSU), chlorophyll $a$ concentration ( $\mu \mathrm{g} \mathrm{I}^{-1}$ ) and turbidity (nephelometer turbidity units, NTU), and were recorded from August 2005 until May 2006. For a more detailed explanation refer to Gardner (2013).

\subsection{Satellite data of chlorophyll a and suspended matter concentrations}

Satellite data of near surface chlorophyll $a$ concentrations $\left(\mu \mathrm{I} \mathrm{I}^{-1}\right)$ and total gravimetric suspended sediment $\left(\mathrm{mg} \mathrm{l}^{-1}\right)$ were obtained for two sites in Wellington Harbour and two sites in the Cook Strait (Figure 1). 
The Wellington Harbour sites were located $\sim 1 \mathrm{~km} \mathrm{SW}$ of Matiu/Somes Island (-41.2665 S, 174.8485 E) where the Wellington Harbour CTD data were collected and $\sim 1 \mathrm{~km}$ east of Point Gordon, Scorching Bay, where the mussels were collected for feeding experiments $(-41.2984$ S, 174.8499 E). The Cook Strait locations were $\sim 1 \mathrm{~km}$ off shore of VUCEL (-41.3559 S, 174.7606 E) where the CTD data were recorded and the feeding experiments took place. The second location was $10 \mathrm{~km}$ off-shore of VUCEL (-41.4406 S, 174.7582 E) in the Cook Strait. Data were collected from July 2002 until April 2014; there was generally a few hundred to a maximum of 1500 data points collected for each site. Data were mean averaged on a monthly basis per year and an overall monthly average was calculated.

Chlorophyll a concentrations were derived from phytoplankton absorption, and total suspended matter was derived from backscatter. The data collected were the log-mean of the nearest 4 data points to each location. If there was more than one satellite overpass per day then the data were log-averaged (Matt Pinkerton of NIWA, personal comment, November 3, 2014). The ocean colour satellite data used were courtesy of NASA Goddard Space Flight Center, and derived from the Moderate Resolution Imaging Spectrometer (MODIS) project. The products were provided by Matt Pinkerton at the National Institute of Water and Atmospheric Research Ltd (NIWA), Wellington.

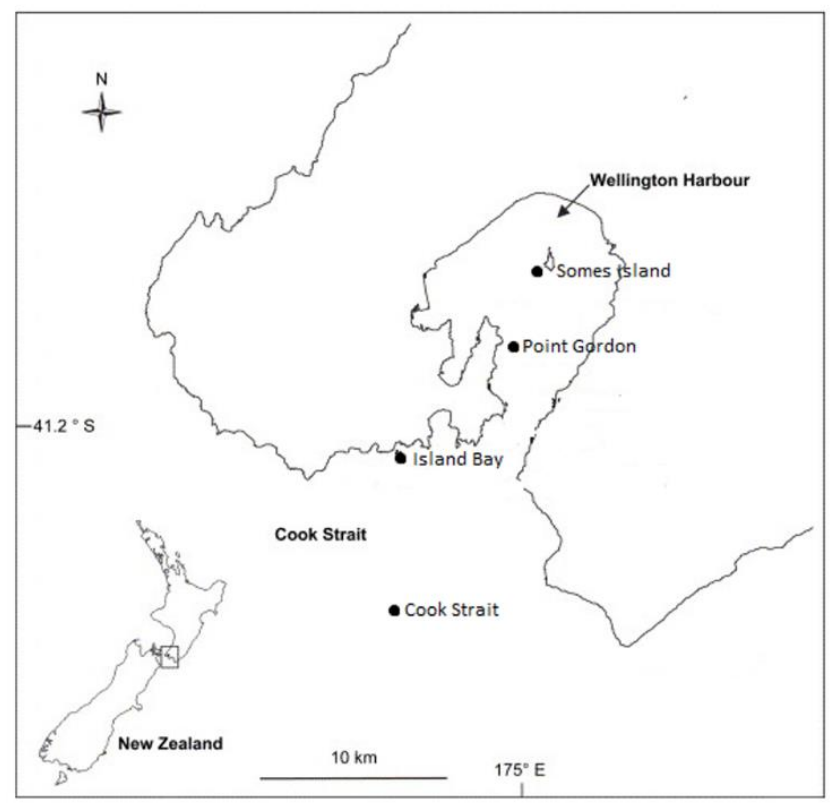

Figure 1. Map of locations of sites for satellite data for total suspended sediment and chlorophyll a. Adapted from Helson et al. (2007). 


\section{Feeding Experiments}

\section{Study facilities}

Mussels were collected from Point Gordon, just north of Scorching Bay in Wellington Harbour during summer, autumn and winter 2014. Forty of both Perna canaliculus and Mytilus galloprovincialis were collected and then transported to either Victoria University Coastal Ecology Lab (VUCEL) in Island Bay which is located on Cook Strait or to Cawthron's Aquaculture Park in Glenduan, Nelson (Figure 2). Mussels transported to Nelson were kept dry and cool until arrival which was within 24 hours of collection.

Mussel shells were cleared of all epibionts when first collected. Mussels were kept at natural densities in plastic aquaria and fed with a constant supply of unfiltered seawater from either the Cook Strait when at VUCEL or from the enriched pond water at Cawthron's Aquaculture Park. The pond water at Cawthron is filled with raw seawater from Tasman Bay, and fertilised to enhance the natural phytoplankton community that is present in that water supply. It is a carefully monitored process ensuring that the ponds are not over or under fertilised. Mussels were left to acclimatise for 5-10 days before experiments began. The experiments were run for five days at each site during each season. Originally a Wellington Harbour raw seawater site was to be used for the following experiment but due to the closure of NIWA's Mahanga Bay hatchery and the unavailability of the Greta Point laboratory I used Cawthron's fertilised ponds seawater as a high quality diet comparison to the low quality diet of the seawater at Island Bay (refer to Gardner $(2000,2013)$ for further site details).

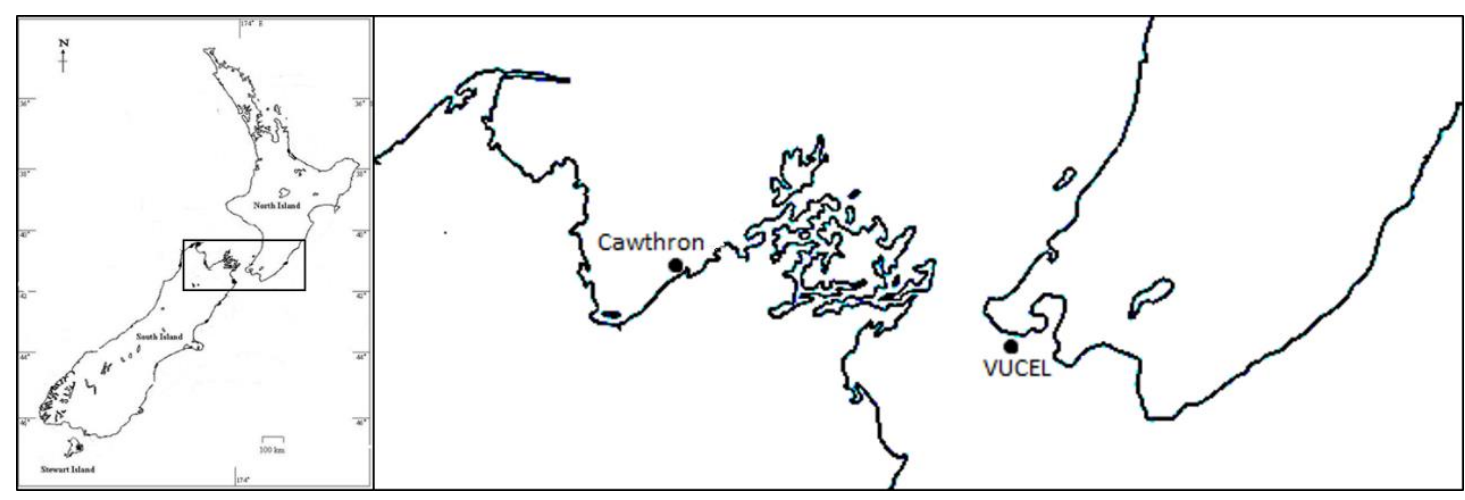

Figure 2. Map showing locations of mussel feeding experiments. Cawthron Aquaculture Park is located on Tasman Bay, Nelson. VUCEL is located in Island Bay (Cook Strait). 


\subsection{Water Column and Seston Characteristics}

To determine seston characteristics $3 \times 1 \mathrm{~L}$ water samples were collected three times per day during each day of each feeding experiment. Each $1 \mathrm{~L}$ water sample was filtered onto a 47 $\mathrm{mm}$ pre-ashed, pre-weighed Whatman GF/C filter and dried for 24 hours at $60{ }^{\circ} \mathrm{C}$. Filters were then weighed to determine total particulate matter (TPM), then ashed at $500{ }^{\circ} \mathrm{C}$ for $6-24$ hours and weighed to determine particulate inorganic matter (PIM). Particulate organic matter (POM) was calculated as:

$$
\mathrm{POM}=\mathrm{TPM}-\mathrm{PIM}
$$

Percent organic matter (PCOM) was estimated as the percent of TPM that is organic and was calculated as:

$$
\mathrm{PCOM}=\left(\frac{\mathrm{POM}}{\mathrm{TPM}}\right) * 100
$$

A CTD was used to record temperature $\left({ }^{\circ} \mathrm{C}\right)$, salinity (PSU), chlorophyll $a$ concentration $(\mu \mathrm{g}$ $\mathrm{I}^{-1}$ ) and turbidity (NTU) at 5 minute intervals during each experiment. Means were taken for morning (08:00-10:55), midday (11:00-13:55), afternoon (14:00-17:00) and for the whole day (08:00-17:00). In Nelson the CTD was placed in the seawater ponds (no data are available for the summer). At VUCEL the CTD was placed in $60,000 \mathrm{~L}$ tank that holds unfiltered seawater pumped straight from Cook Strait and which is replaced every four to eight hours (Gardner 2013).

Particle counts were recorded three times per day using a Z1 Coulter Counter which was fitted with a $100 \mu \mathrm{m}$ aperture tube and which counted all particles within the size range 2 to $60 \mu \mathrm{m}$ equivalent spherical diameter (ESD) in $1 \mathrm{~mL}$ of the sample.

\subsection{Clearance Rate}

The clearance rate (CR) of each mussel is defined as the amount of water completely cleared of particles animal ${ }^{-1}$ hour $^{-1}$ (Widdows and Johnson 1988). CR was determined for 30 Perna canaliculus and 30 Mytilus galloprovincialis across a wide size range, as mussels were randomly selected during collection. The experiments were carried out at VUCEL using unfiltered seawater pumped directly from the Cook Strait and at Cawthron using seawater 
pumped from the enriched ponds. Experiments were carried out during summer, autumn and winter and each experiment ran for five days.

A flow through system was used to determine the $C R$, following the experiment set up of Gardner $(2000,2002)$ and was designed to be portable for ease of movement between Island Bay and Nelson. Seawater was filtered through a $2 \mathrm{~mm}$ mesh to remove large particles (generally above the maximum size limit accepted by mussels) and pumped into a $20 \mathrm{~L}$ header tank with an outflow pipe to maintain a constant water pressure. The header tank was connected to 13 chambers by $3 \mathrm{~mm}$ plastic tubing.

The 13 chambers consisted of three $1 \mathrm{~L}$ chambers, five $500 \mathrm{~mL}$ chambers and five $250 \mathrm{~mL}$ chambers, and one mussel was assigned to each chamber depending on its shell length. During each experiment one chamber was left empty as a control; this chamber was randomly selected each experiment. The flow rate though the chambers was controlled by restricting the flow from the header tank and varied depending on the size of the chamber. The flow rate through the $1 \mathrm{~L}$ chambers varied between $170-220 \mathrm{ml} \mathrm{min}^{-1}$, the flow rate for the 500 $\mathrm{ml}$ chambers was $130-160 \mathrm{ml} \mathrm{min}-1$ and in the $250 \mathrm{~mL}$ chamber the flow rate was $80-120$ $\mathrm{mL} \mathrm{min}$. The flow rate was checked at the start of each experiment. The water entered the chamber at the bottom and the outflow was a $3 \mathrm{~mm}$ plastic tube at the opposite end but at the top of the chamber to ensure no faecal production was lost. Mussels were positioned facing the inflow but were free to move during each experiment.

Three times a day (morning, midday and afternoon) $20 \mathrm{~mL}$ of water was collected from the outflow tube of each chamber to determine particle counts using a Z1 Coulter Counter at VUCEL and a Beckman-Coulter Multisizer 4 Coulter Counter at Cawthron. Both were fitted with a $100 \mu \mathrm{m}$ aperture tube and counted all particles within the size range 2 to $60 \mu \mathrm{m}$ ESD in $1 \mathrm{~mL}$ of the sample.

At each time of sampling the CR was calculated for each mussel using the equation

$$
\mathrm{CR}=\left(\frac{(\mathrm{Cc}-\mathrm{Cm})}{\mathrm{Cc}}\right) * \mathrm{FR}
$$

where the clearance rate (CR) is measured in $\mathrm{L} \mathrm{h}^{-1}, \mathrm{Cc}$ is the number of particles from the control chamber, $\mathrm{Cm}$ is the number of particles form the chambers containing a mussel and $F R$ is the flow rate in $L h^{-1}$. 
At the end of each day the mussels were shucked and soft flesh was dried at $60{ }^{\circ} \mathrm{C}$ for 24 48 hours depending on their size, to determine dry body weight. Because a large size range of mussels was used the CR was standardised (CRs) to $1 \mathrm{~g}$ dry tissue weight.

\subsection{Absorption Efficiency}

The absorption efficiency ( $A E)$ compares the organic matter in the food and the faeces, and represents how efficiently the organic matter from the seston is absorbed by the mussels (Widdows and Johnson 1988). At the end of each day faecal material from each mussel was carefully collected with a pipette. All faecal material was filtered onto a pre-ashed, preweighed Whatman GF/C filter and dried at $60{ }^{\circ} \mathrm{C}$ for 24 hours. The filters were weighed to determine the dry weight, then ashed at $500{ }^{\circ} \mathrm{C}$ for $6-24$ hours and weighed to determine ash-free dry weight.

If pseudofaeces were produced it was collected from each chamber and processed in the same manner as faeces. The time of collection was recorded so the rate of pseudofaecal production could be calculated.

Individual AE was calculated for each mussel using the Conover ratio (Conover 1966):

$$
\mathrm{AE}=\frac{\mathrm{F}-\mathrm{E}}{(1-\mathrm{E}) * \mathrm{~F}}
$$

where $F$ is the ash-free dry weight to dry weight ratio of seston supplied to the mussels and $E$ is the ash-free dry weight to dry weight ratio of faeces.

\subsection{Net Energy Budget}

Net energy budget (NEB) was calculated for each individual mussel according to Widdows and Johnson (1988). NEB is the energy available for somatic growth and reproductive growth after routine metabolic costs have been accounted for. A positive NEB means a net energy gain for that mussel, while a negative NEB reflects an energy loss. Ammonia excretion was not included in this experiment as it only represents 1-2\% of energy expenditure (Tam 2012), so NEB will be slightly over estimated. NEB is calculated as: 


$$
\mathrm{NEB}=(\mathrm{C} * \mathrm{AE})-\mathrm{R}
$$

where $\mathrm{C}$ is the total energy consumed and is calculated as:

$$
C=\left(C R s\left(g^{-1} h^{-1}\right) *\left(\operatorname{POM}\left(\mathrm{mg} \mathrm{l}^{-1}\right)\right)-\operatorname{PSF}(\operatorname{POM~mg~l-1})\right)^{*} 23\left(\mathrm{~J} \mathrm{mg} \mathrm{l}^{-1}\right)
$$

$R$ is the respiratory energy used and is calculated as:

$$
\mathrm{R}=\mathrm{VO}_{2}\left(\mathrm{ml} \mathrm{O}_{2} \mathrm{~g}^{-1} \mathrm{~h}^{-}\right) * 20.33\left(\mathrm{~J} \mathrm{ml}^{-1}\right)
$$

It is important to include pseudofaeces (PSF) if produced. The temperature-dependant $\mathrm{VO}_{2}$ values calculated by Helson and Gardner (2007) were used in this study to calculate NEB values.

\section{Analysis of particle properties using FlowCAM}

\subsection{Particle Properties}

Three times daily ( $9 \mathrm{am}, 12 \mathrm{pm}$ and $3 \mathrm{pm}$ ) $45 \mathrm{ml}$ water samples were collected from the outflow pipe of each chamber holding a mussel and the control chamber. Three $\mathrm{ml}$ of $1 \%$ Lugol's iodine was used to preserve the samples before storage in a dark, cold place within an hour of collection. All samples were stored in this manner until processed using the bench top Flow Cytometer and Microscope (FlowCAM) (Fluid Imaging Technologieshttp://www.fluidimaging.com). The FlowCAM combines the capabilities of flow cytometry, microscope and imagine analysis. It takes photos and counts every particle that flows past the field of view, and has been designed for rapid analysis of samples (Sieracki et al. 1998, Álvarez et al. 2011).

Before samples were processed they were filtered through a $53 \mu \mathrm{m}$ mesh to remove any material that could block the flow cell (50 $\mu$ m aperture). Each chamber containing a mussel had one water sample processed per day, and all three samples were processed for the control chambers and later averaged.

The settings on the FlowCAM were kept constant following preliminary testing of image quality. Samples were analysed at x200 magnification, x20 objective and run through a $50 \mu \mathrm{m}$ flow cell. Auto-image mode was used to analyse the samples; this mode takes a fixed number of photos per second and captures all particles that are photographed. 
The frames per second was set to 5 and each sample was run for 30 minutes at a speed of $0.005 \mathrm{ml} / \mathrm{min}$, thereby capturing all particles in the size range 2-50 $\mu \mathrm{m}$ ESD. For each sample $0.15 \mathrm{ml}$ was sampled and 9,000 photographs were taken. Visual Spreadsheet, the FlowCAM software, extracts and stores each individually photographed particle in a collage with all the other particles that have been recorded in that sample. This collage of photos is called a list which was saved for every sample. Each list was visually inspected for particles that had been captured twice or artefacts such as air bubbles that were removed from the list.

The FlowCAM software produces a dataset of all the particle properties for each sample. These properties were recorded and used to compare the control chambers to the chambers that had mussels feeding in them to determine if the overall composition of seston differed (see Appendix B2 for particle properties recorded).

\subsection{Seston composition}

Once all samples had been processed, libraries were built using the FlowCAM Visual Spreadsheet. Libraries were created by selecting the most commonly occurring particles in each sample and storing them in individual libraries. The libraries contained 20 to 100 images. From the libraries filters were built for each library on the overall characteristics of the particles stored in that library. The characteristics were particle properties such as circular fit, ESD, length, compactness, intensity etc.

The filters were then used to build a classification template. The classification template consisted of the 21 classes (see Appendix B4). Each class was built from the filters which had previously been derived from the libraries. An auto-classify was run on each sample; this uses the classification template to sort all the particles in the samples into one of the 21 classes. After the auto-classification was performed on the sample, each category was checked to make sure no particles had been incorrectly classified. If particles had been sorted into the wrong class they were manually removed and re-classified.

Five cultured microalgae samples (Chaetoceros calcitrans, Chaetoceros muelleri, Isochrysis galbana, Skeletonema sp. and Tetraselmis $s p$ ) were obtained from Cawthron and processed using the FlowCAM to check library construction and classification accuracy, as well as to add 
known classes of microalgae to the library for use in particle identification. The particles captured from these known microalgae cultures were stored as libraries, used as filters and turned into classes in the classification template. They were also used to determine the effectiveness of the auto-classification. Mixed samples of known microalgae were sampled and then auto-classified using the classification template. This classification was then visually inspected. This method showed that the auto-classification was accurate but some manual classification of particles was still needed.

\section{Statistical Analysis}

Data analysis was conducted using the statistical program PRIMER (Plymouth Routines in Multivariate Ecological Research). All data were tested for normality and equal variances but most data failed either one or both of these assumptions needed for ANOVA analysis. As a consequence PERMANOVA (permutational MANOVA) was employed to analyse the data; 999 permutations were used to test for differences in the data set. PERMANOVA does not assume normal distribution, and uses distance matrices relevant to the data and permutations so it does not rely on distributions (Anderson et al. 2008).

\section{Environmental characteristics of Wellington Harbour and Cook Strait}

A two-way PERMANOVA with the factors site (Wellington Harbour and Cook Strait) and month (monthly average for August 2005 to May 2006 for the CTD data, and January to December 2002 to 2014 for satellite data) based on a similarity matrix constructed using Euclidean distance (because of many zeros in the data set) and 999 permutations was used to test for differences in the CTD and satellite derived data. If significant differences were found, pairwise testing using PERMANOVA was used to further investigate the differences.

\section{Feeding experiments}

A two-way PERMANOVA with the factors site (Island Bay and Nelson) and season (summer, autumn and winter) and their interaction was tested. A similarity matrix was constructed using Bray-Curtis similarity index (the data contained no zeros) and 999 permutations were used to test for differences. If significant differences were found, pairwise testing using 
PERMANOVA was to further investigate the location of differences. For CRs, AE and NEB this analysis was run using both species, and then repeated just using just M. galloprovincialis or P. canaliculus.

\section{Analysis of particle properties using FlowCAM}

\subsection{Particle Properties}

The first analysis completed for particle properties used PERMANOVA to test if there was a difference between the particle properties of the control chamber compared to experimental chambers. Next a PERMANOVA with the factors site (Island Bay and Nelson) and season (autumn and winter) and their interaction was tested. A similarity matrix was constructed using Euclidean distance and 999 permutations were used to test for differences. If significant differences were found, pairwise testing using PERMANOVA was to further investigate the location of differences. This analysis was run using both species, and then repeated using just M. galloprovincialis or P. canaliculus.

\subsection{Seston composition}

Because of the number of zeros in the dataset and the large range of values among the samples the data were fourth-root transformed before being analysed using PERMANOVA. The first test completed for particle types was to determine if difference between the particle types of the control chamber compared to experimental chambers. Next a PERMANOVA with the factors site (Island Bay and Nelson) and season (autumn and winter) and their interaction was tested. A similarity matrix was constructed using Euclidean distance and 999 permutations were used to test for differences. If significant differences were found, pairwise testing using PERMANOVA was used to further investigate the differences. This analysis was run using both species, and then repeated just using either the data from $\mathrm{M}$. galloprovincialis or P. canaliculus. Finally each particle type classification was analysed using PERMANOVA to test for differences between the experiment and control chambers. If there was as significant difference pairwise testing was completed. 


\section{Results}

\section{Environmental characteristics of Wellington Harbour and Cook Strait}

\subsection{Water samples}

Unfortunately there was not enough time to process the weekly water samples collected from Wellington Harbour and Island Bay with the FlowCAM. These will be processed at a later date.

\subsection{Water column variables}

Two-way PERMANOVA revealed that temperature, turbidity, chlorophyll $a$ and salinity were all significantly different for site (Wellington Harbour and Cook Strait), month (August to May) and for the site $\mathrm{x}$ month interaction.

Sea water temperature was higher on average in Wellington Harbour compared to the Cook Strait (Table 1). Post-hoc PERMANOVA pairwise testing showed that the Wellington Harbour and Cook Strait were significantly different in all months except April, May and September. Temperatures increased steadily at both sites over the summer months, peaking in mid-summer (January) (Figure 3).

Wellington Harbour had a three times higher mean turbidity value than the Cook Strait, although concentrations were very variable. Wellington Harbour and the Cook Strait were significantly different during each month for which data were recorded. At both sites February had the highest mean turbidity.

Chlorophyll $a$ was almost ten times greater overall in Wellington Harbour than Cook Strait (Table 1). The sites were different during all months. Wellington Harbour chlorophyll a peaked during February, and the highest concentrations continued into early autumn. Another peak occurred during October. In the Cook Strait the maximum chlorophyll $a$ was recorded during November and remained at this level throughout summer (Figure 3).

Salinity was also significantly different between the locations during each month, except for March. On average the salinity was lower in Wellington Harbour and more variable when compared to the Cook Strait. 
Table 1. Mean ( \pm SD) temperature, turbidity, chlorophyll $a$ and salinity for Island Bay (Cook Strait) and Matiu/Somes Island (Wellington Harbour).

\begin{tabular}{ccccc}
\cline { 2 - 5 } Site & $\begin{array}{c}\text { Temperature } \\
\left({ }^{\circ} \mathbf{C}\right)\end{array}$ & $\begin{array}{c}\text { Turbidity } \\
(\mathbf{N T U})\end{array}$ & $\begin{array}{c}\text { Chlorophyll } \boldsymbol{a} \\
\left(\boldsymbol{\mu \mathrm { g } \mathrm { I } ^ { - 1 } )}\right.\end{array}$ & $\begin{array}{c}\text { Salinity } \\
(\text { PSU) }\end{array}$ \\
\hline \hline Island Bay & 14.68 & 9.13 & 0.39 & 34.20 \\
Matiu/Somes & $(1.70)$ & $(7.51)$ & $(0.17)$ & $(1.26)$ \\
Island & 15.15 & 26.57 & 3.69 & 32.46 \\
\hline \hline
\end{tabular}



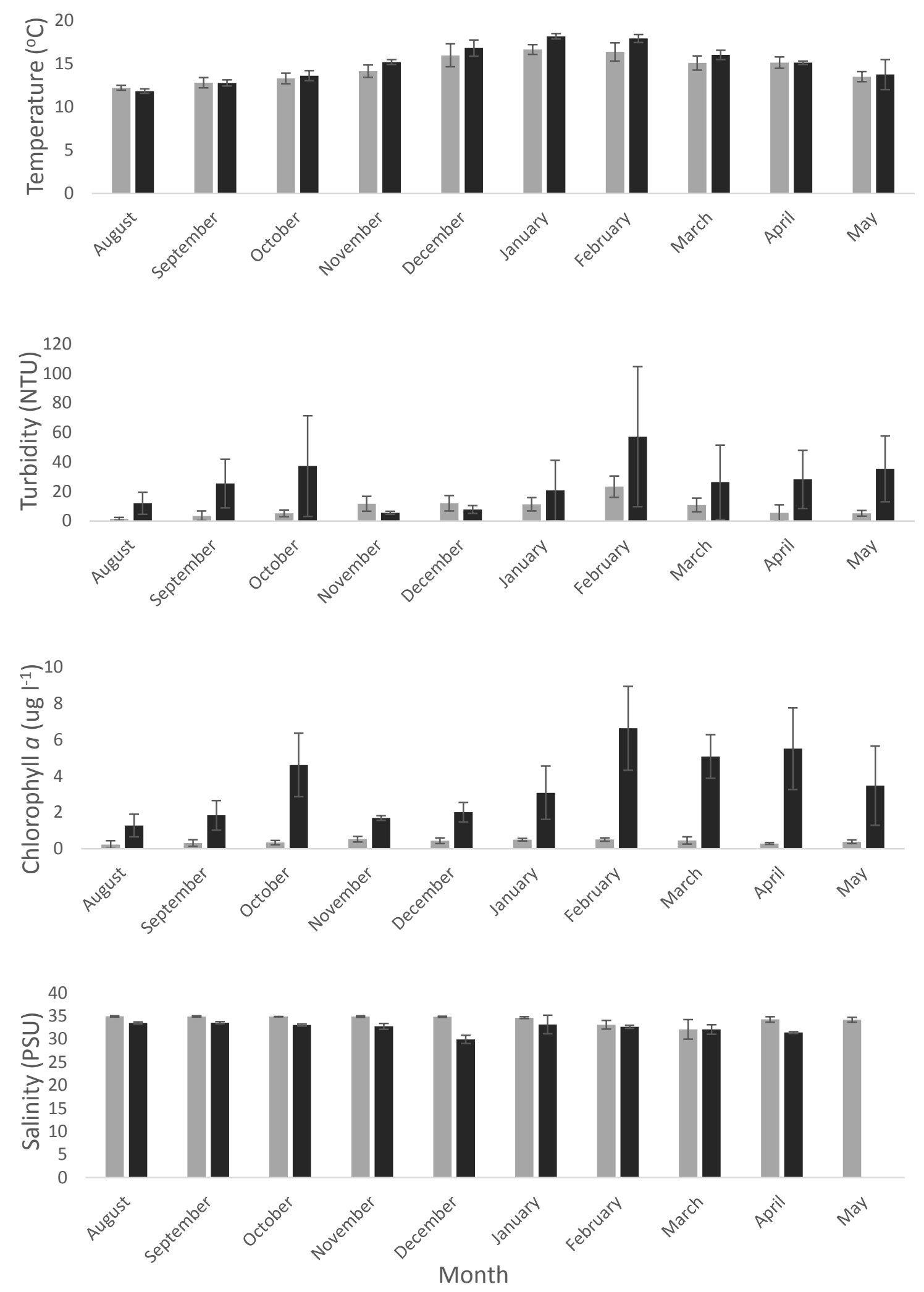

Figure 3. Mean $( \pm S D)$ of temperature, turbidity, chlorophyll $a$ and salinity in Island Bay, Cook Strait, light grey) and Matiu/Somes Island, Wellington Harbour (black). August to December is data from 2005, January to May is 2006 data. No available information for salinity in Cook Strait in May due to inaccuracies in recorded values. 


\subsection{Satellite data of chlorophyll a and suspended matter}

Total suspended sediment was significantly different between sites (Pseudo-F=39.84, $\mathrm{P}=0.001$ ), but not for months or the interaction between site and month. Post-hoc pairwise comparisons showed that all sites were significantly different to each other $(P=0.001)$ except for Matiu/Some Island (yearly mean \pm SD $=1.66 \pm 0.30)$ and Scorching Bay $(1.58 \pm 0.27)$ which are both located in Wellington Harbour. Both Harbour sites had a higher total suspended sediment than the Cook Strait locations (Island Bay $=1.00 \pm 0.26$ and Cook Strait $=0.67 \pm$ 0.16). The Cook Strait sites total suspended sediment was highest during the winter and early spring months. The overall yearly means display a gradient of decreasing total suspended sediment with distance from the Harbour (Figure 4, Appendix A2).

Chlorophyll $a$ was significantly different amongst sites (Pseudo-F=79.48, $\mathrm{P}=0.001$ ) but not months. All sites were significantly different to each other $(P=0.001)$ except for the Wellington Harbour sites, for which the Matiu/Somes Island yearly average was $5.36 \pm 1.06 \mu \mathrm{g} \mathrm{I}^{-1}$ and Scorching Bay was $5.78 \pm 1.35 \mu \mathrm{g} \mathrm{I}^{-1}$. The Wellington Harbour sites had higher chlorophyll $a$ concentrations than the Cook Strait sites. Island Bay had $1.54 \pm 0.53 \mu \mathrm{g} \mathrm{I}^{-1}$ and further out in the Cook Strait that site had the lowest yearly average of $0.47 \pm 0.10 \mu \mathrm{g} \mathrm{I}^{-1}$ which was over ten times less than the Harbour sites. Cook Strait chlorophyll $a$ concentrations remained constant throughout the year, whereas the values at Island Bay increased in late autumn and peaked in June. The Wellington Harbour sites showed a greater variation in concentrations throughout the year as they increased in late autumn/winter and again in October (Figure 4, Appendix A1). 


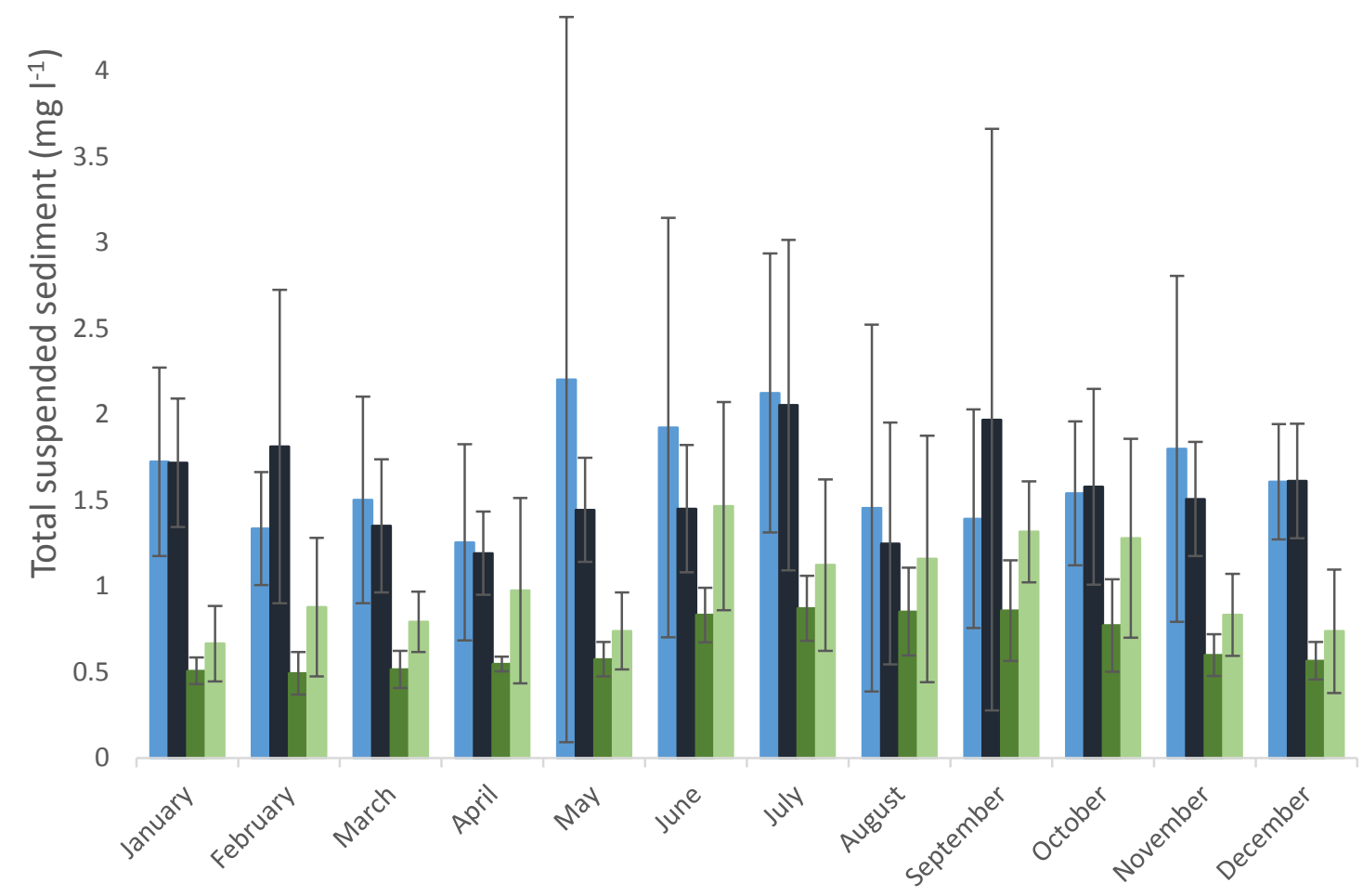

16

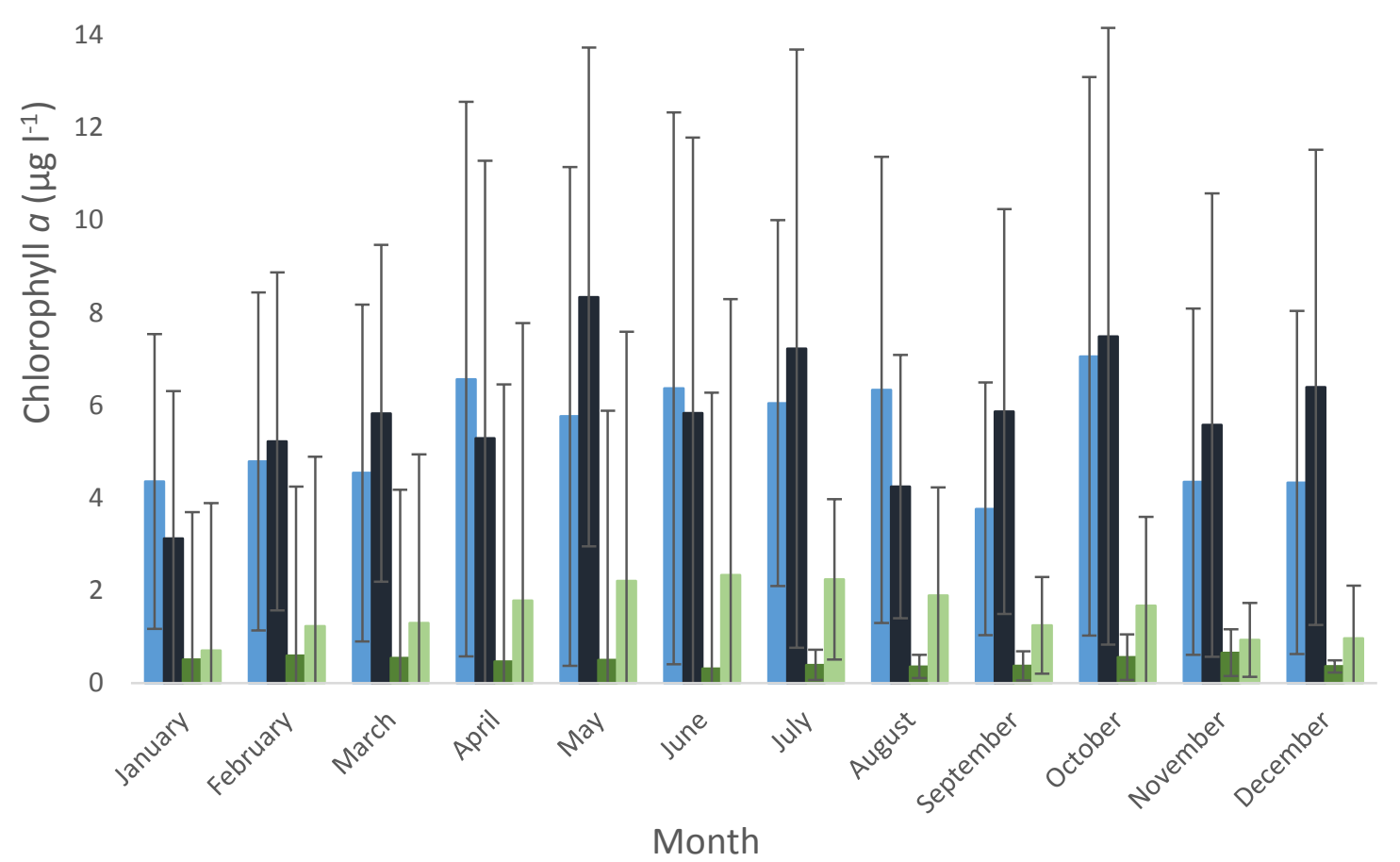

Figure 4. Mean monthly ( $\pm \mathrm{SD})$ total suspended sediment $\left(\mathrm{mg} \mathrm{l}^{-1}\right)$ and Chlorophyll $a\left(\mu \mathrm{g}^{-1}\right)$ at Matiu/Somes Island (light blue), Scorching Bay (dark blue), Cook Strait (dark green) and Island Bay (light green). Monthly averages are based on data from 2002 - 2014. 


\section{Feeding Experiments}

\subsection{Water Column and Seston Characteristics}

\section{Seston Characteristics}

All seston characteristics were significantly different between seasons. The TPM was highest in autumn for Island Bay, and highest in winter in Nelson (Table 2, Figure 5). The lowest values for both locations were recorded during summer. There was no significant difference between sites: particle count, POM and PCOM were highest during autumn at both locations. PCOM and particle counts were significantly different between sites. Autumn in Island Bay had the highest overall POM and PCOM, and autumn in Nelson had the highest seasonal mean particle count at 107,228.18 which was almost double any other particle count (Table 2).

Table 2. Mean ( \pm SD) particle count (particles per $\mathrm{ml}$ ), total particulate matter $\mathrm{mg} \mathrm{l}^{-1}(\mathrm{TPM})$, particulate organic matter $\mathrm{mg} \mathrm{l}^{-1}$ (POM) and percent organic matter (PCOM) at Island Bay (Cook Strait) and Nelson (Tasman Bay) during summer, autumn and winter.

\begin{tabular}{cccccc}
\hline \multirow{2}{*}{ Site } & Season & Particle Count & TPM & POM & PCOM \\
\hline \hline \multirow{2}{*}{ Island Bay } & Summer & $17,876.20$ & 16.96 & 3.86 & 22.65 \\
& & $(3853.90)$ & $(1.10)$ & $(0.40)$ & $(1.41)$ \\
& \multirow{3}{*}{ Autumn } & $35,732.91$ & 20.09 & 7.72 & 38.66 \\
& & $(17438.26)$ & $(0.58)$ & $(0.39)$ & $(1.99)$ \\
& \multirow{2}{*}{ Winter } & $28,306.30$ & 19.87 & 4.34 & 21.84 \\
& & $(12152.83)$ & $(1.49)$ & $(0.37)$ & $(1.09)$ \\
\hline \multirow{2}{*}{ Nelson } & \multirow{2}{*}{ Summer } & $(40,355.28$ & 16.80 & 4.96 & 27.31 \\
& & $(4297.25)$ & $(1.53)$ & $(1.15)$ & $(1.46)$ \\
& \multirow{3}{*}{ Autumn } & $107,228.18$ & 18.97 & 5.65 & 29.75 \\
& & $(21410.52)$ & $(0.95)$ & $(0.88)$ & $(3.58)$ \\
& \multirow{2}{*}{ Winter } & $59,468.13$ & 20.34 & 5.26 & 25.93 \\
& & $(12749.53)$ & $(0.97)$ & $(0.32)$ & $(0.39)$ \\
\hline \hline
\end{tabular}




\section{Water characteristics}

Sea water temperature was lower on average at Island Bay and was higher with less variability at Nelson (Table 3). The temperature was significantly different between site (Pseudo-F=5.18, $\mathrm{P}=0.042$ ), season and for the site $\mathrm{x}$ season interaction (both $\mathrm{P}=0.001$ ). Unfortunately chlorophyll $a$, turbidity and salinity were not recorded for summer in Nelson. Chlorophyll $a$ was significantly different between sites (Pseudo-F=66.96, $\mathrm{P}=0.001$ ), with the chlorophyll $a$ content being higher in Nelson during autumn (over six times greater) and winter (over 10 times greater). In Island Bay the highest chlorophyll $a$ value was recorded in autumn and the lowest during winter.

The sites were not different for turbidity but the seasons displayed variation (Pseudo$\mathrm{F}=14.08, \mathrm{P}=0.001$ ). At Island Bay turbidity was highest during autumn and lowest in winter. Nelson showed the same pattern, the autumn value was nine times greater than that for winter. Salinity varied between site (Pseudo-F=14.84, $P=0.002$ ), season (Pseudo-F=8.83, $P=0.001$ ) and as a function of the site $x$ season interaction (Pseudo-F=7.31, $P=0.017$ ). It was highest in Island Bay and at both locations autumn had the highest mean salinity value (Table 3).

Table 3. Mean $( \pm S D)$ temperature $\left({ }^{\circ} \mathrm{C}\right)$, turbidity (NTU), chlorophyll $a\left(\mu \mathrm{g}^{-1}\right)$ and salinity (PSU) at Island Bay (Cook Strait) and Nelson (Tasman Bay) during summer, autumn and winter.

\begin{tabular}{|c|c|c|c|c|c|}
\hline Site & Season & Temperature & Chlorophyll a & Turbidity & Salinity \\
\hline \multirow{6}{*}{ Island Bay } & \multirow{2}{*}{ Summer } & 15.08 & 0.38 & 3.70 & 34.33 \\
\hline & & $(0.38)$ & $(0.15)$ & (1.70) & $(0.07)$ \\
\hline & \multirow{2}{*}{ Autumn } & 14.65 & 0.44 & 5.78 & 34.94 \\
\hline & & $(0.12)$ & $(0.07)$ & (3.20) & $(0.06)$ \\
\hline & \multirow{2}{*}{ Winter } & 11.63 & 0.26 & 1.08 & 34.07 \\
\hline & & $(0.25)$ & $(0.04)$ & $(0.07)$ & $(0.36)$ \\
\hline \multirow{6}{*}{ Nelson } & \multirow{2}{*}{ Summer } & 16.54 & \multirow{2}{*}{ NA } & \multirow{2}{*}{ NA } & \multirow{2}{*}{ NA } \\
\hline & & (0.79) & & & \\
\hline & \multirow{2}{*}{ Autumn } & 17.38 & 2.77 & 5.80 & 34.09 \\
\hline & & $(1.75)$ & (1.47) & (2.99) & $(0.43)$ \\
\hline & \multirow{2}{*}{ Winter } & 10.00 & 2.83 & 0.64 & 33.92 \\
\hline & & (0.95) & (NA) & (0.37) & $(0.27)$ \\
\hline
\end{tabular}



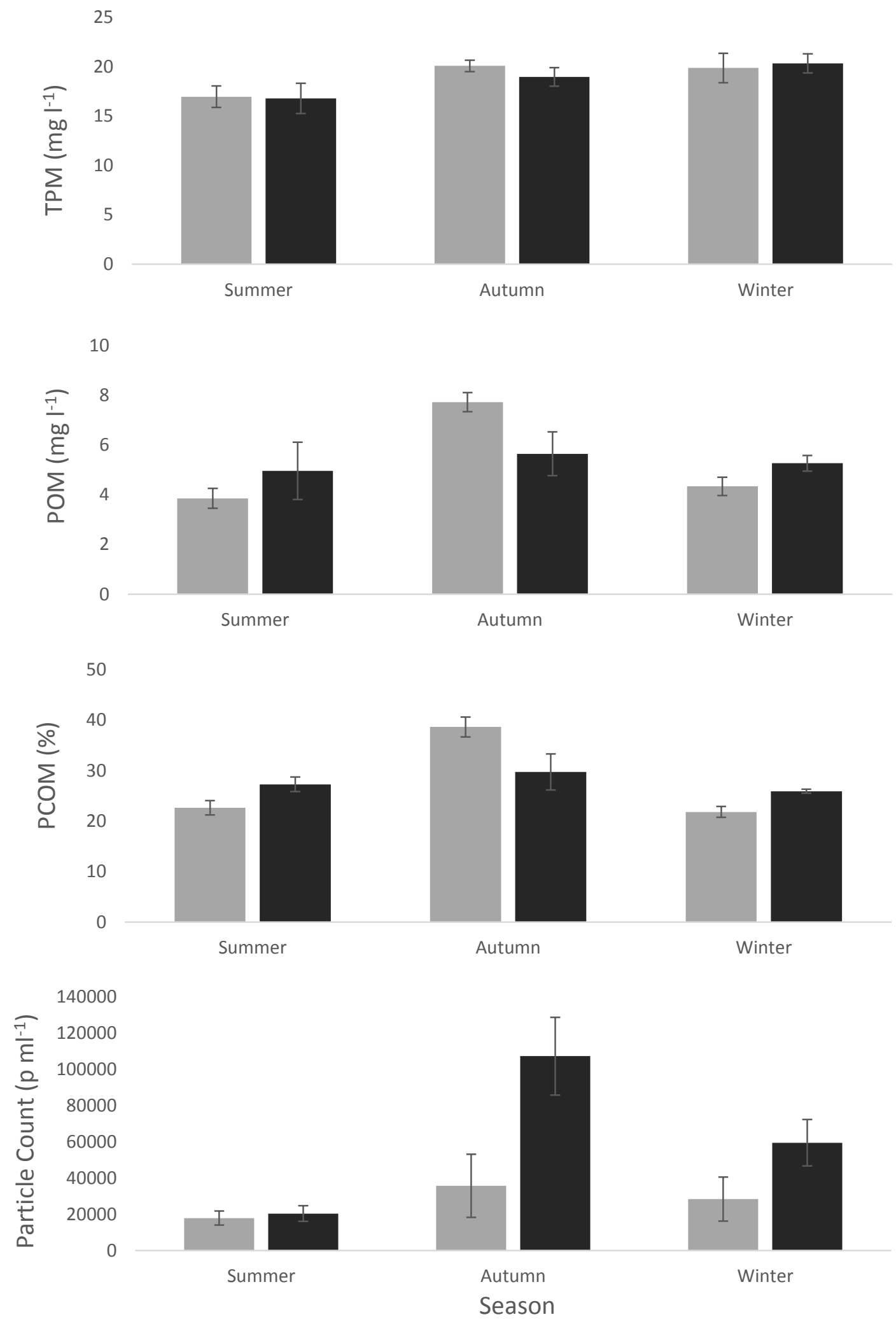

Figure 5. Mean ( \pm SD) of TPM $\left(\mathrm{mg} \mathrm{l}^{-1}\right)$, POM $\left(\mathrm{mg} \mathrm{l}^{-1}\right)$, PCOM (\%) and particle count (number of particles $\mathrm{ml}^{-1}$ ) in summer, autumn and winter. Island Bay is shown in light grey and Nelson is shown in black. 
Mussel Physiology

PERMANOVA was performed for CRs, AE and NEB using the factors site (Island Bay and Nelson), season (summer, autumn and winter) and the interaction for site and season. Each physiological characteristic was then analysed for each species separately. Post-hoc pairwise testing was performed using PERMANOVA.

Table 4. Mean ( \pm SD) standardised clearance rates in $\mathrm{g}^{-1} \mathrm{~h}^{-1}(\mathrm{CRs})$, absorption efficiencies (AE) and net energy budget in $\mathrm{J} \mathrm{g}^{-1} \mathrm{~h}^{-1}$ (NEB) at Island Bay and Nelson during summer, autumn and winter for M. galloprovincialis and $P$. canaliculus.

\begin{tabular}{|c|c|c|c|c|c|}
\hline Site & Season & Species & CRs & $\mathrm{AE}$ & NEB \\
\hline \multirow{12}{*}{ Island Bay } & Summer & M. galloprovincialis & 2.80 & 0.14 & 32.75 \\
\hline & & & (1.11) & $(0.27)$ & (65.35) \\
\hline & & P. canaliculus & 3.81 & 0.24 & 83.98 \\
\hline & & & (1.08) & $(0.18)$ & (67.51) \\
\hline & Autumn & M. galloprovincialis & 2.10 & 0.33 & 127.63 \\
\hline & & & $(0.70)$ & $(0.18)$ & (85.97) \\
\hline & & P. canaliculus & 2.67 & 0.55 & 246.67 \\
\hline & & & $(0.67)$ & $(0.14)$ & (77.74) \\
\hline & Winter & M. galloprovincialis & 2.68 & 0.11 & 28.03 \\
\hline & & & $(0.87)$ & $(0.16)$ & (42.32) \\
\hline & & P. canaliculus & 2.69 & 0.20 & 47.58 \\
\hline & & & $(0.44)$ & $(0.15)$ & (41.12) \\
\hline \multirow{12}{*}{ Nelson } & Summer & M. galloprovincialis & 2.12 & 0.21 & 40.44 \\
\hline & & & $(0.58)$ & $(0.12)$ & (30.32) \\
\hline & & P. canaliculus & 2.14 & 0.24 & 49.05 \\
\hline & & & $(0.48)$ & $(0.16)$ & (39.29) \\
\hline & Autumn & M. galloprovincialis & 2.07 & 0.30 & 76.27 \\
\hline & & & (0.91) & $(0.14)$ & (68.95) \\
\hline & & P. canaliculus & 1.47 & 0.37 & 63.85 \\
\hline & & & $(0.34)$ & $(0.10)$ & (26.21) \\
\hline & Winter & M. galloprovincialis & 2.19 & 0.22 & 48.90 \\
\hline & & & (0.59) & $(0.08)$ & (32.41) \\
\hline & & P. canaliculus & 1.97 & 0.25 & 52.11 \\
\hline & & & $(0.42)$ & $(0.08)$ & $(21.40)$ \\
\hline
\end{tabular}




\subsection{Clearance rate}

The mean CRs of mussels of both species was significantly different between sites (Pseudo$\mathrm{F}=82.70, \mathrm{P}=0.001$ ) and amongst seasons (Pseudo- $\mathrm{F}=17.59, \mathrm{P}=0.001$ ) but not for the interaction of site and season (Figure 6). Mussels fed during summer had the highest CRs of $2.72 \mathrm{I} \mathrm{g}^{-1} \mathrm{~h}^{-1}( \pm 0.56)$ and the mussel held at Island Bay had higher CRs values compared to those held at Nelson (Figure 6, Table 4). Pairwise testing revealed that at Island Bay the mussels CRs during all seasons were significantly different to each, whereas in Nelson only summer and winter were not significantly different $(P=0.52)$.

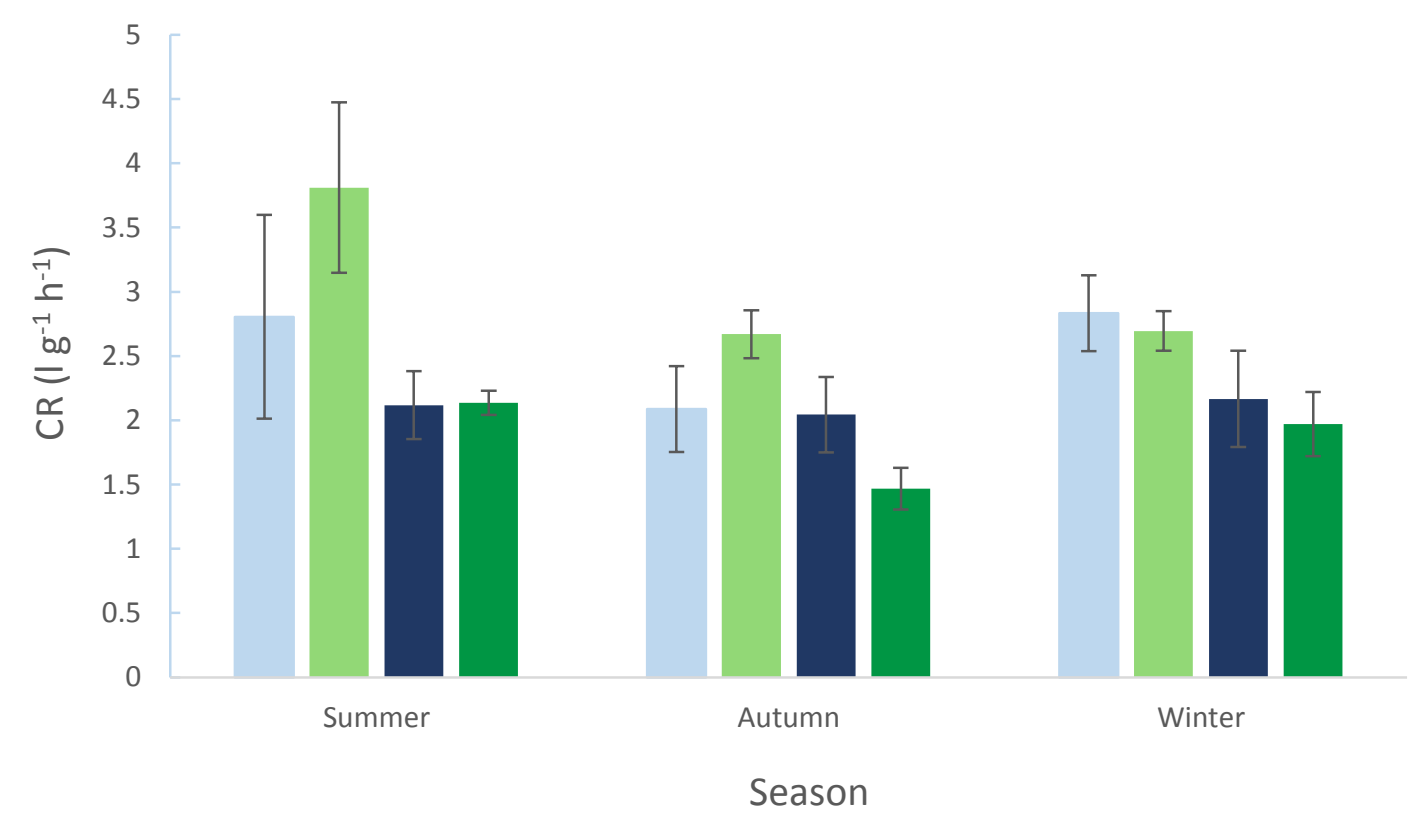

Figure 6. Standardised clearance rate (CRs) in $\mathrm{I} \mathrm{g}^{-1} \mathrm{~h}^{-1}$ (mean $\pm \mathrm{SD}$ ) of $P$. canaliculus and $M$. galloprovincialis during three seasons at Island Bay and Nelson. Light blue $=M$. galloprovincialis in Island Bay, light green $=P$. canaliculus in Island Bay, dark blue $=M$. galloprovincialis in Nelson and dark green $=P$. canaliculus in Nelson.

\section{Mytilus galloprovincialis}

CRs was significantly different between site and amongst seasons for M.galloprovincialis. The interaction for site and season was not significantly different (Figure 6). The CRs of mussels in Island Bay was significantly different to the CRs of mussels in Nelson during summer and 
winter. The CRs was highest during winter at Island Bay $\left(2.83 \mathrm{I} \mathrm{g}^{-1} \mathrm{~h}^{-1}\right)$ and lowest in autumn at Nelson $\left(2.04 \mathrm{I} \mathrm{g}^{-1} \mathrm{~h}^{-1}\right)$. The mean CRs for M. galloprovincialis was $2.33 \mathrm{I} \mathrm{g}^{-1} \mathrm{~h}^{-1}( \pm 0.33)$.

\section{Perna canaliculus}

Site, season and site $x$ season were all significantly different for CRs $(P=0.001)$. CRs of mussels in Island Bay was higher than those in Nelson for each season. In Island Bay summer was significantly different to autumn and winter and had the highest CRs of all seasons at $3.81 \mathrm{I} \mathrm{g}^{-}$ ${ }^{1} h^{-1}( \pm 0.66)$. In Nelson autumn was significantly different to each season, and had the lowest CRs of $1.47 \mathrm{I} \mathrm{g}^{-1} \mathrm{~h}^{-1}( \pm 0.16)$.

\subsection{Absorption Efficiency}

Mean AE of all mussels was not significantly different between mussels held at Island Bay and Nelson, but was significantly different amongst the season (Pseudo-F=53.08, $P=0.001$ ) and the interaction between site and season (Pseudo- $\mathrm{F}=10.68, \mathrm{P}=0.001$ ). AE was higher in autumn than summer or winter $(P=0.001), A E$ in summer and winter were not different significantly different (Figure 7). This pattern occurred at Island Bay and Nelson. The highest $A E$ value occurred in autumn at Island Bay; this value was double that recorded in summer or winter (Table 4). When the $A E$ value was averaged for each site there was no difference between the mussels at Island Bay $(0.26 \pm 0.16)$ and the mussels in Nelson $(0.27 \pm 0.06)$.

\section{Mytilus galloprovincialis}

Absorption efficiency was significantly different between sites and amongst seasons (Figure 7). At each site $A E$ of mussels in autumn was significantly different to those in summer and winter. $\mathrm{AE}$ was highest at both sites (Island Bay=0.31, Nelson $=0.30$ ), and the lowest was during winter at Island Bay (0.12). The mean AE for M. galloprovincialis was $0.22( \pm 0.09)$.

\section{Perna canaliculus}

Site, season and the site $x$ season interaction were all significantly different for AE (Figure 7). Autumn was significantly different to summer and winter $(P=0.001)$, and had the highest mean $\mathrm{AE}(0.46 \pm 0.15)$. Autumn was also the only season where Island Bay and Nelson were significantly different to each other $(t=5.95, P=0.001)$. The mean $A E$ for all $P$. canaliculus was $0.31( \pm 0.18)$. 


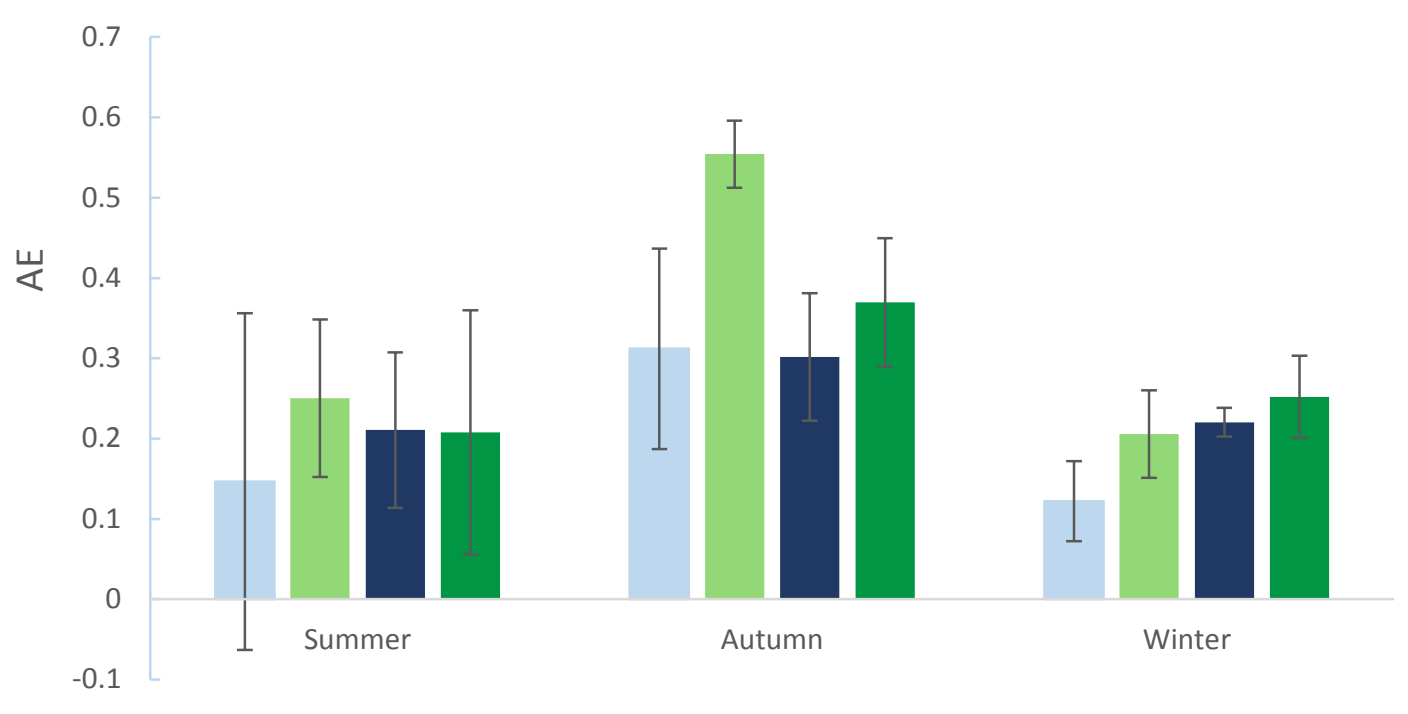

Season

Figure 7. Absorption efficiency (mean $\pm \mathrm{SD}$ ) of $P$. canaliculus and $M$. galloprovincialis during three seasons at Island Bay and Nelson. Light blue $=M$. galloprovincialis in Island Bay, light green $=P$. canaliculus in Island Bay, dark blue $=M$. galloprovincialis in Nelson and dark green $=P$. canaliculus in Nelson.

\subsection{Net Energy Budget}

Site, season and the site $x$ season interaction were all significantly different $(P=0.001)$ (Figure 8). PERMANOVA pairwise analysis revealed that autumn was significantly different to all seasons in Island Bay and in Nelson. The NEB for all mussels was not significantly different between Island Bay and Nelson in summer and winter. The NEB was different between the locations in autumn $(t=8.09, P=0.001)$. The highest NEB occurred in mussels held at Island Bay during autumn and the lowest in winter (Table 4).

\section{Mytilus galloprovincialis}

NEB was significantly different between seasons (Pseudo- $F=23.57, P=0.001$ ); at each site autumn was significantly different to summer and winter (Figure 8). The highest NEB was recorded at Island Bay during autumn $\left(123.9 \mathrm{~J} \mathrm{~g}^{-1} \mathrm{~h}^{-1}\right)$, which was over three times the values recorded in summer and winter, and double the mean NEB value $(59.00 \pm 37.69)$. Mussels held in Nelson had the greatest NEB values during summer and winter, and Island Bay was higher during autumn. 


\section{Perna canaliculus}

For $P$. canaliculus NEB site, season and the site $\mathrm{x}$ season interaction were all significantly different $(\mathrm{P}=0.001)$ (Figure 8). In summer $(\mathrm{t}=2.56 \mathrm{P}=0.008)$ and autumn $(\mathrm{t}=12.20, \mathrm{P}=0.001)$ Island Bay had a higher NEB on average than Nelson. In Island Bay all seasons were significantly different to each other, with autumn having the highest value of $252.96 \mathrm{~J} \mathrm{~g} \mathrm{~g}^{-1} \mathrm{~h}^{-1}$ (Figure 8), which was almost three times larger than the second highest NEB of $89.28 \mathrm{~J} \mathrm{~g}^{-1} \mathrm{~h}^{-1}$ which was recorded during summer at Island Bay. In Nelson the NEB variation throughout the seasons was not significantly different.

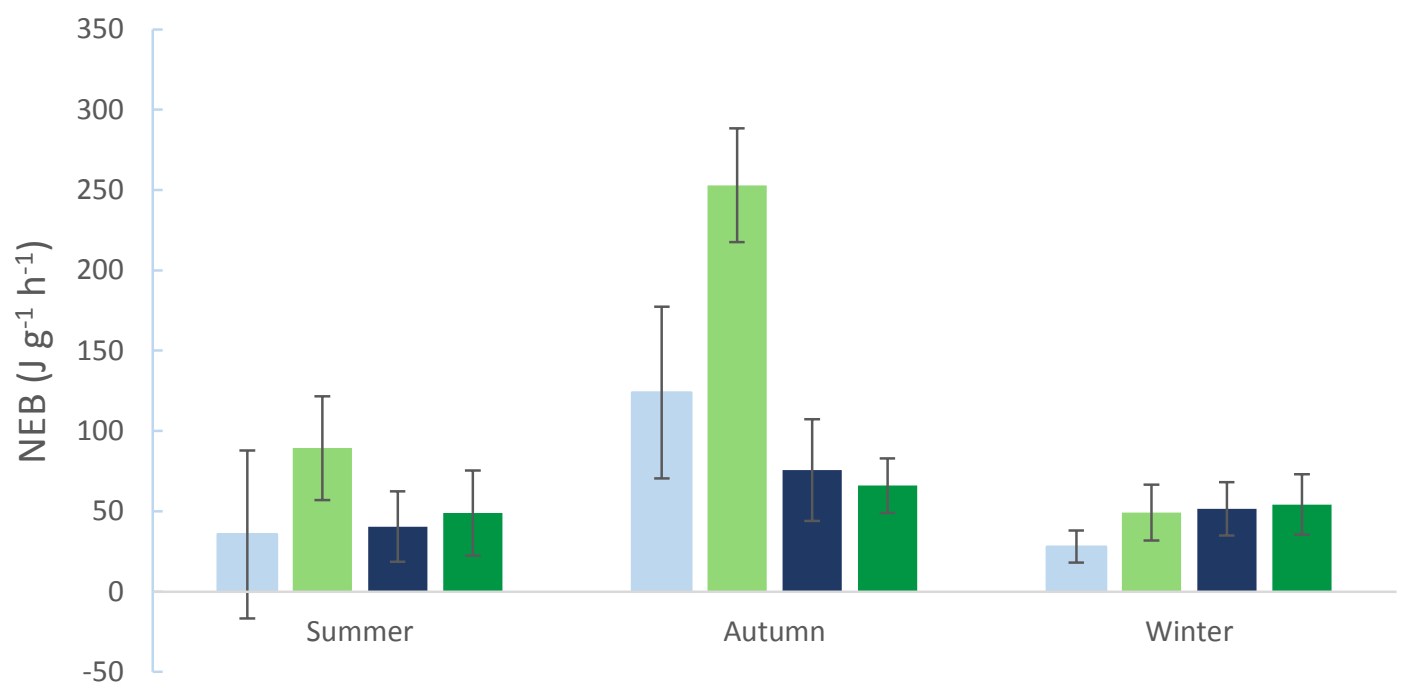

Season

Figure 8. Net Energy Budget in $\mathrm{J} \mathrm{g}^{-1} \mathrm{~h}^{-1}$ (mean $\pm \mathrm{SD}$ ) of $P$. canaliculus and M. galloprovincialis during three seasons at Island Bay and Nelson. Light blue $=$ M. galloprovincialis in Island Bay, light green $=P$. canaliculus in Island Bay, dark blue $=M$. galloprovincialis in Nelson and dark green $=P$. canaliculus in Nelson .

\section{Analysis of particle properties using FlowCAM}

\subsection{Particle Properties}

The FlowCAM records the overall particle properties from each water sample run through it. Particle properties were comprised of 16 variable such as compactness, length, volume etc. (for more particle properties see Appendix B2 and B3). The first test performed was 
PERMANOVA which tested for a difference in particle properties in the outflow of the control chamber and the outflow of the experimental chamber which held feeding mussels, to determine if the mussels were selecting certain particle properties. There was a significant difference in the particle properties in the outflow water of the control chamber and the experimental chambers (Pseudo- $\mathrm{F}=4.58, \mathrm{P}=0.032$ ).

The next test was to determine if the particle properties in the outflow water were different to the control in both species of mussels ( $P$. canaliculus and M. galloprovincialis). There was a significantly different at $\alpha=0.10$ but not $\alpha=0.05$ (Pseudo- $F=2.77, P=0.057$ ). The particle properties in the water that had been fed on by $M$. galloprovincialis were not significantly different to the particle properties that had been fed on by $P$. canaliculus or to the control. The particle properties that had been fed on by $P$. canaliculus were significantly different to those that came out of the control chamber $(t=2.34, \mathrm{P}=0.03)$.

When the particle properties in the water that had been fed on by M. galloprovincialis were compared to the controls with both site combined there was a significantly different at $\alpha=0.10$ (Pseudo-F=2.81, $P=0.09$ ). The sites were then tested separately. The particle properties did not differ between the experimental chambers and the control when fed sea water from Island Bay, suggesting that no preferential selection occurred in terms of particle properties. When fed water from Nelson (Cawthron's enriched pond water) there was a significant difference in the particle properties that had been fed on by M. galloprovincialis and the control chambers (Pseudo-F=3.84, $\mathrm{P}=0.04$ ).

Particle properties that had been fed on by $P$. canaliculus were compared to the particle properties in the outflow water of the control chambers at each site. When fed at Island Bay the particle properties were not different, suggesting that no selection of different particle properties occurred at this site. When fed at Nelson on the enriched pond water there was a significant difference in the particle properties that $P$. canaliculus were feeding on (Pseudo$F=7.46, P=0.009)$. 


\subsection{Seston Composition}

The seston composition (types of particles present) were determined by using the outflow water from the control chambers and the chambers holding mussels (water that had been grazed on by mussels). The first test performed was a PERMANOVA comparing the particle types in the outflow of the control chambers and the experimental chambers (all mussels regardless of species). There was a significant difference (Pseudo- $F=2.80, P=0.051$ ) at $\alpha=0.10$. Post-hoc pairwise testing compared the particle type in the control chambers to the particle types that had been fed on by $M$. galloprovincialis and $P$. canaliculus found that both species were different to the control $(P=0.001)$ but did not differ between each other $(P=0.143)$. Which provides evidence of particle selection by both species of mussels, and evidence that they are tending to select the same type of particles.

For all particle types the control always had a higher amount of particles $\mathrm{ml}^{-1}$ than either mussel species (see Appendix B3). There was one case where P. canaliculus had a higher amount than the control, for Isochrysis sp which was by one particle (3.24 \pm 13.22 vs $2.12 \pm$ 7.53). M. galloprovincialis often had the second highest amount of particles per $\mathrm{ml}$ and $P$. canaliculus appeared to be feeding on the most particles as particles $\mathrm{ml}^{-1}$ were often lowest.

The particle type concentrations in the outflow of the control chambers were not significantly different to the particle types in the outflow of the experimental chambers holding M. galloprovincialis when feeding at Island Bay. The only occasion when the particle types were significantly different in the control chambers to the experimental chambers was during autumn when being held in Nelson (Pseudo-F=2.47, $\mathrm{P}=0.036$ ).

In the outflow of the experimental chambers holding $P$. canaliculus the particle types were significantly different to the particle types in the control chamber when being held at Island Bay and Nelson during autumn and winter (each case $\mathrm{P}=0.05$ or less).

Each of the 21 particle types were individually tested for $M$. galloprovincialis and $P$. canaliculus at Island Bay and Nelson during autumn (which was found to have the highest overall NEB) and winter (which has the lowest overall NEB). PERMANOVA was used to test if the concentrations of the particle type were significantly different in the outflow of the control chamber to the outflow of the chamber which had a mussel feeding in it. The results are presented in Tables 5-8. 
Table 5. Results from PERMANOVA differences in each particle type (particles $\mathrm{ml}^{-1}$ ) between the control chamber and the experimental chambers of $M$. galloprovincialis or $P$. canaliculus during autumn in Island Bay. Bold denotes significant differences at $\alpha=0.10$

\begin{tabular}{|c|c|c|c|c|}
\hline & \multicolumn{2}{|c|}{ Mytilus galloprovincialis } & \multicolumn{2}{|c|}{ Perna canaliculus } \\
\hline & Pseudo- $F$ & $\mathrm{P}($ perm $)$ & Pseudo- F & $\mathrm{P}($ perm $)$ \\
\hline Circular particles & $5.03 \mathrm{E}-4$ & 1 & 4.11 & 0.071 \\
\hline Small Circular & 1.15 & 0.32 & 2.74 & 0.116 \\
\hline Short \& thick & 1.69 & 0.20 & 2.37 & 0.139 \\
\hline Long \& Thin & 3.90 & 0.042 & 2.45 & 0.137 \\
\hline Pennate Diatoms & 7.07 & 0.171 & 7.07 & 0.143 \\
\hline Triangular & 3.78 & 0.075 & 3.26 & 0.58 \\
\hline Thecate dinoflagellates & 0.62 & 0.372 & 0.62 & 0.376 \\
\hline Species A & NA & NA & NA & NA \\
\hline Species B & NA & NA & 0.16 & 1 \\
\hline Species C & 0.74 & 0.40 & 1.91 & 0.271 \\
\hline Clear Pennate Diatoms & NA & NA & NA & NA \\
\hline Ciliates & NA & NA & NA & NA \\
\hline Skeletonema sp. & NA & NA & NA & NA \\
\hline Tetraselmis sp. & 7.07 & 0.13 & 7.07 & 0.166 \\
\hline Chaetoceros muelleri & 7.07 & 0.15 & 0.55 & 0.387 \\
\hline Chaetoceros calcitrans & NA & NA & NA & NA \\
\hline Isochrysis sp. & NA & NA & NA & NA \\
\hline Detritus & 0.44 & 0.50 & 1.51 & 0.206 \\
\hline Inorganic particles & 0.93 & 0.33 & 2.91 & 0.105 \\
\hline 2-5 $\mu \mathrm{m}$ unidentified & 0.83 & 0.38 & 1.39 & 0.274 \\
\hline 5-50 $\mu \mathrm{m}$ unidentified & 0.28 & 0.65 & 0.95 & 0.304 \\
\hline
\end{tabular}


Table 6. Results from PERMANOVA differences in each particle type (particles $\mathrm{ml}^{-1}$ ) between the control chamber and the experimental chambers of $M$. galloprovincialis or $P$. canaliculus during winter in Island Bay. Bold denotes significant differences at $\alpha=0.10$.

\begin{tabular}{|c|c|c|c|c|}
\hline & \multicolumn{2}{|c|}{ Mytilus galloprovincialis } & \multicolumn{2}{|c|}{ Perna canaliculus } \\
\hline & Pseudo- F & $\mathbf{P}($ perm $)$ & Pseudo- F & $\mathbf{P}($ perm $)$ \\
\hline Circular particles & 1.41 & 0.212 & 4.82 & 0.057 \\
\hline Small Circular & 1.58 & 0.212 & 2.70 & 0.117 \\
\hline Short \& thick & 0.11 & 0.754 & 1.29 & 0.262 \\
\hline Long \& Thin & 0.67 & 0.412 & 0.31 & 0.526 \\
\hline Pennate Diatoms & 6.20 & 0.048 & 1.00 & 0.562 \\
\hline Triangular & 3.58 & 0.054 & 3.75 & 0.062 \\
\hline Thecate dinoflagellates & 1.39 & 0.276 & 0.44 & 1 \\
\hline Species A & NA & NA & NA & NA \\
\hline Species B & NA & NA & NA & NA \\
\hline Species C & 0.34 & 1 & 0.34 & 1 \\
\hline Clear Pennate Diatoms & 0.34 & 1 & 0.34 & 1 \\
\hline Ciliates & NA & NA & NA & NA \\
\hline Skeletonema sp. & NA & NA & NA & NA \\
\hline Tetraselmis sp. & NA & NA & NA & NA \\
\hline Chaetoceros muelleri & 0.16 & 1 & NA & NA \\
\hline Chaetoceros calcitrans & NA & NA & NA & NA \\
\hline Isochrysis sp. & NA & NA & NA & NA \\
\hline Detritus & 3.83 & 0.06 & 6.56 & 0.013 \\
\hline Inorganic particles & 1.47 & 0.24 & 1.72 & 0.174 \\
\hline 2-5 $\mu \mathrm{m}$ unidentified & 0.75 & 0.37 & 3.06 & 0.088 \\
\hline 5-50 $\mu \mathrm{m}$ unidentified & 0.33 & 0.59 & 0.65 & 0.46 \\
\hline
\end{tabular}


Table 7. Results from PERMANOVA differences in each particle type (particles $\mathrm{ml}^{-1}$ ) between the control chamber and the experimental chambers of $M$. galloprovincialis or $P$. canaliculus during autumn in Nelson. Bold denotes significant differences at $\alpha=0.10$.

\begin{tabular}{|c|c|c|c|c|}
\hline & \multicolumn{2}{|c|}{ Mytilus galloprovincialis } & \multicolumn{2}{|c|}{ Perna canaliculus } \\
\hline & Pseudo- F & $P($ perm $)$ & Pseudo- F & $\mathrm{P}($ perm $)$ \\
\hline Circular particles & 1.52 & 0.254 & 2.47 & 0.13 \\
\hline Small Circular & 2.67 & 0.13 & 3.79 & 0.059 \\
\hline Short \& thick & 1.59 & 0.223 & 2.83 & 0.095 \\
\hline Long \& Thin & 1.06 & 0.305 & 1.26 & 0.297 \\
\hline Pennate Diatoms & 1.31 & 0.274 & 1.91 & 0.176 \\
\hline Triangular & 1.45 & 0.215 & 0.65 & 0.438 \\
\hline Thecate dinoflagellates & 4.30 & 0.061 & 7.72 & 0.005 \\
\hline Species A & 0.47 & 1 & 0.21 & 1 \\
\hline Species B & 0.29 & 0.596 & 4.39 & 0.033 \\
\hline Species C & 2.14 & 0.176 & 4.94 & 0.029 \\
\hline Clear Pennate Diatoms & 10.76 & 0.008 & 6.47 & 0.012 \\
\hline Ciliates & 18.86 & 0.02 & 18.86 & 0.016 \\
\hline Skeletonema sp. & 2.59 & 0.093 & 6.35 & 0.011 \\
\hline Tetraselmis sp. & 0.73 & 0.551 & 1.43 & 0.188 \\
\hline Chaetoceros muelleri & 1.54 & 0.208 & 3.13 & 0.104 \\
\hline Chaetoceros calcitrans & 4.53 & 0.029 & 6.59 & 0.025 \\
\hline Isochrysis sp. & 0.41 & 0.799 & 0.13 & 0.76 \\
\hline Detritus & 2.16 & 0.156 & 1.83 & 0.185 \\
\hline Inorganic particles & 1.64 & 0.221 & 2.59 & 0.113 \\
\hline 2-5 $\mu \mathrm{m}$ unidentified & 4.86 & 0.031 & 7.63 & 0.017 \\
\hline 5-50 $\mu \mathrm{m}$ unidentified & 1.67 & 0.199 & 2.63 & 0.114 \\
\hline
\end{tabular}


Table 8. Results from PERMANOVA differences in each particle type (particles $\mathrm{ml}^{-1}$ ) between the control chamber and the experimental chambers of $M$. galloprovincialis or $P$. canaliculus during winter at Nelson. Bold denotes significant differences at $\alpha=0.10$.

\begin{tabular}{|c|c|c|c|c|}
\hline & \multicolumn{2}{|c|}{ Mytilus galloprovincialis } & \multicolumn{2}{|c|}{ Perna canaliculus } \\
\hline & Pseudo- F & $\mathrm{P}($ perm $)$ & Pseudo- F & $\mathbf{P}($ perm $)$ \\
\hline Circular particles & 1.93 & 0.109 & 2.26 & 0.135 \\
\hline Small Circular & 0.63 & 0.456 & 0.40 & 0.546 \\
\hline Short \& thick & 0.23 & 0.648 & 0.37 & 0.552 \\
\hline Long \& Thin & 0.53 & 0.459 & 1.36 & 0.235 \\
\hline Pennate Diatoms & 1.84 & 0.218 & 2.24 & 0.17 \\
\hline Triangular & 0.90 & 0.296 & 1.26 & 0.292 \\
\hline Thecate dinoflagellates & 3.69 & 0.081 & 1.54 & 0.143 \\
\hline Species A & 1.22 & 0.261 & 1.34 & 0.256 \\
\hline Species B & 1.63 & 0.148 & 0.60 & 0.454 \\
\hline Species C & 3.45 & 0.162 & 6.58 & 0.023 \\
\hline Clear Pennate Diatoms & 2.40 & 0.141 & 3.78 & 0.053 \\
\hline Ciliates & 3.11 & 0.08 & 18.19 & 0.026 \\
\hline Skeletonema sp. & 3.01 & 0.087 & 2.189 & 0.155 \\
\hline Tetraselmis sp. & 2.40 & 0.105 & 1.11 & 0.285 \\
\hline Chaetoceros muelleri & 0.38 & 0.536 & 2.41 & 0.137 \\
\hline Chaetoceros calcitrans & 0.57 & 0.529 & 7.38 & 0.017 \\
\hline Isochrysis sp. & 0.12 & 1 & 6.82 & 0.153 \\
\hline Detritus & 0.78 & 0.363 & 0.78 & 0.398 \\
\hline Inorganic particles & 1.30 & 0.258 & 3.85 & 0.073 \\
\hline 2-5 $\mu \mathrm{m}$ unidentified & 0.47 & 0.542 & 0.60 & 0.431 \\
\hline 5-50 $\mu \mathrm{m}$ unidentified & 0.39 & 0.52 & 2.18 & 0.159 \\
\hline
\end{tabular}


At Island Bay during autumn the particle types that were significantly different in the control outflow water to the outflow of chamber that held and were fed on by $M$. galloprovincialis were the long and thin particles and triangular particles. Only the circular particles were significantly different between the control and water that $P$. canaliculus had grazed on (Table 5, Figure 9). All particle types had a higher concentration in the outflow of the control chamber than chambers that held feeding mussels. Because only these certain particle types were significantly different it suggests selective feeding on these types by the different mussel species.

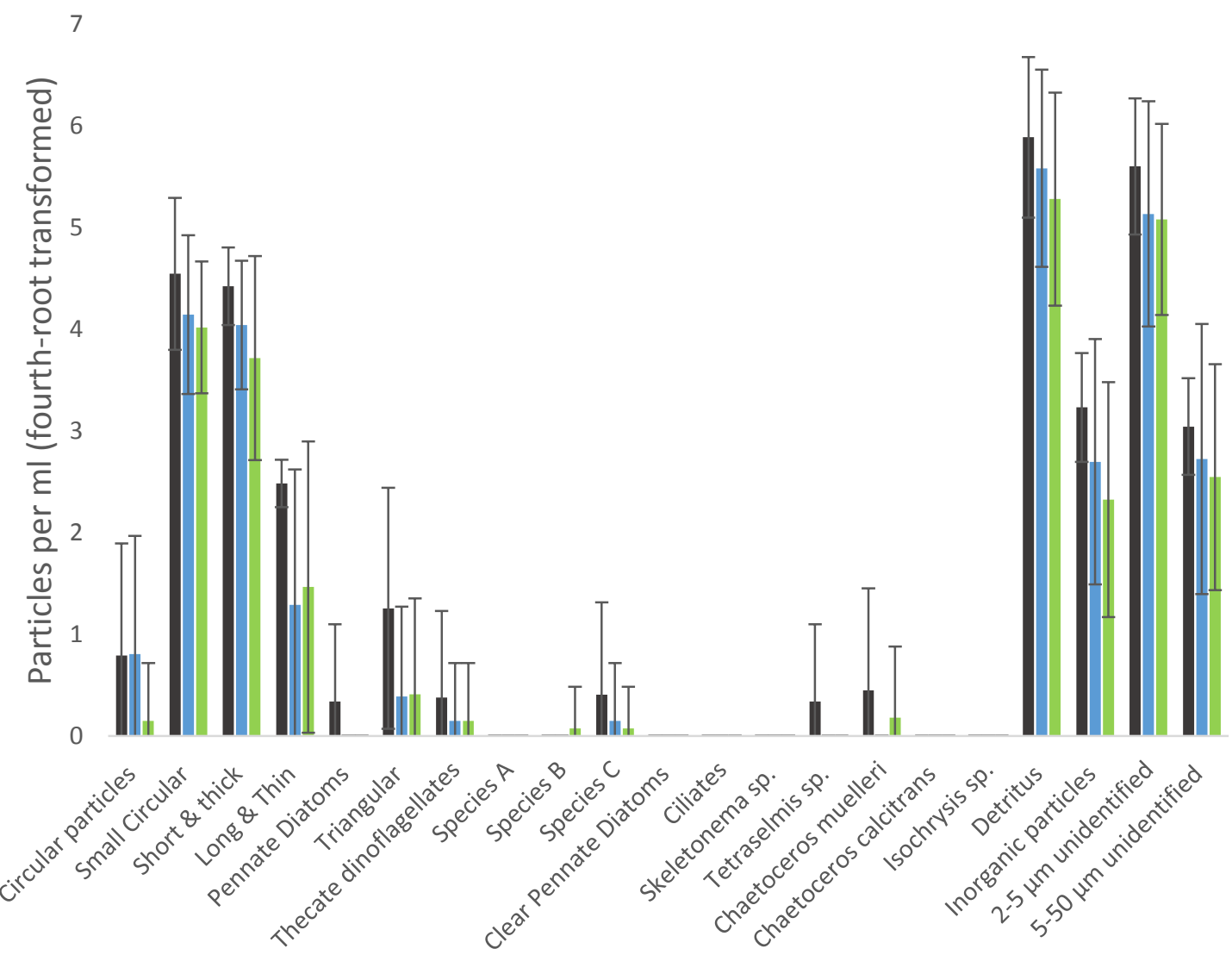

Particle Type

Figure 9. The number of particles per $\mathrm{ml}$ (fourth-root transformed) $\pm \mathrm{SD}$, of particles types recorded in Island Bay during autumn. The blue bars are M. galloprovincialis, the green are $P$. canaliculus and the control is shown in black. 
In Island Bay during winter most particle types were higher (excluding Species C, Clear Pennate Diatoms and C. muelleri) in the outflow of the control chambers than the outflow of chambers holding either M. galloprovincialis or P. canaliculus (Figure 10). The particle types that were significantly different which suggests selective feeding once grazed on by $M$. galloprovincialis were pennate diatoms, triangular particles and detritus. The particles that were selectively grazed on by $P$. canaliculus were circular particles, detritus and unknown particles in the size range 2-5 $\mu \mathrm{m}$ (Table 7). During winter at Island Bay was the only time when both mussel species selectively feed on detritus.

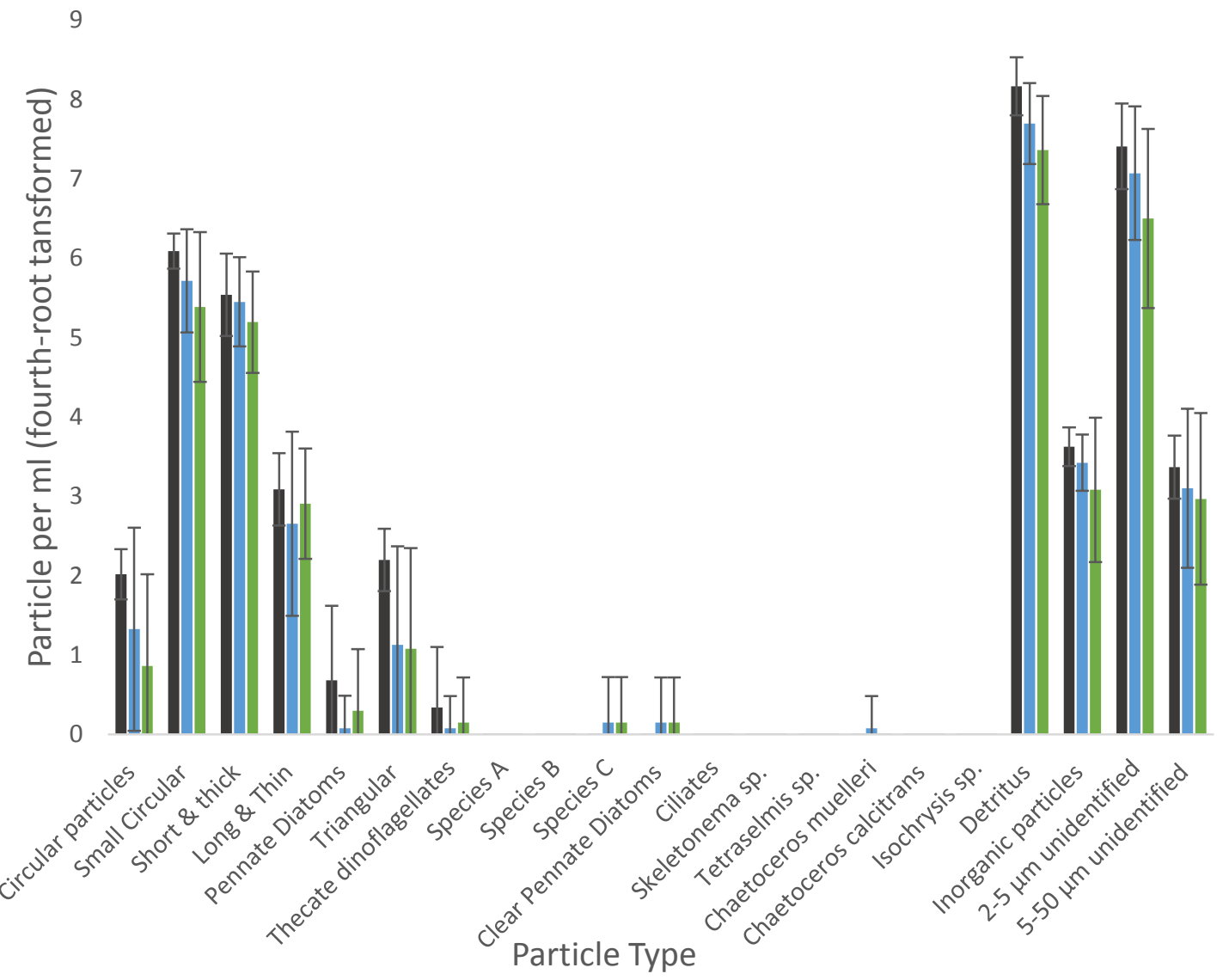

Figure 10. The number of particles per $\mathrm{ml}$ (fourth-root transformed) $\pm \mathrm{SD}$, of particles types recorded in Island Bay during winter. The blue bars are $M$. galloprovincialis, the green are $P$. canaliculus and the control is shown in black.

In Nelson, when mussels were feed on the enriched pond water, during autumn all particle types had higher concentrations in the outflow water of the control chambers than the outflow of water of the experimental chambers which held either M. galloprovincialis or $P$. canaliculus (Figure 11). The particle concentrations that were significantly lower in the 
chambers where M. galloprovincialis were feeding were thecate dinoflagellates, clear pennate diatoms, ciliates, Skeletonema sp., C. calcitrans and unknown particles in the size range 2-5 $\mu \mathrm{m}$. The particle types that were significantly lower in the outflow of $P$. canaliculus compared to the control chambers were small circular particles, short and thick particles, thecate dinoflagellates, Species B, Species C, clear pennate diatoms, ciliates, Skeletonema sp., C. calcitrans and unknown particles in the size range 2-5 $\mu \mathrm{m}$. Due to these particles being significantly different (Table 7) and the other particle types not being although they were lower than the control chamber, it suggests that the mussels are selectively feeding on these particle types over the others recorded when being fed on the Cawthron's enriched pond water in Nelson during autumn.

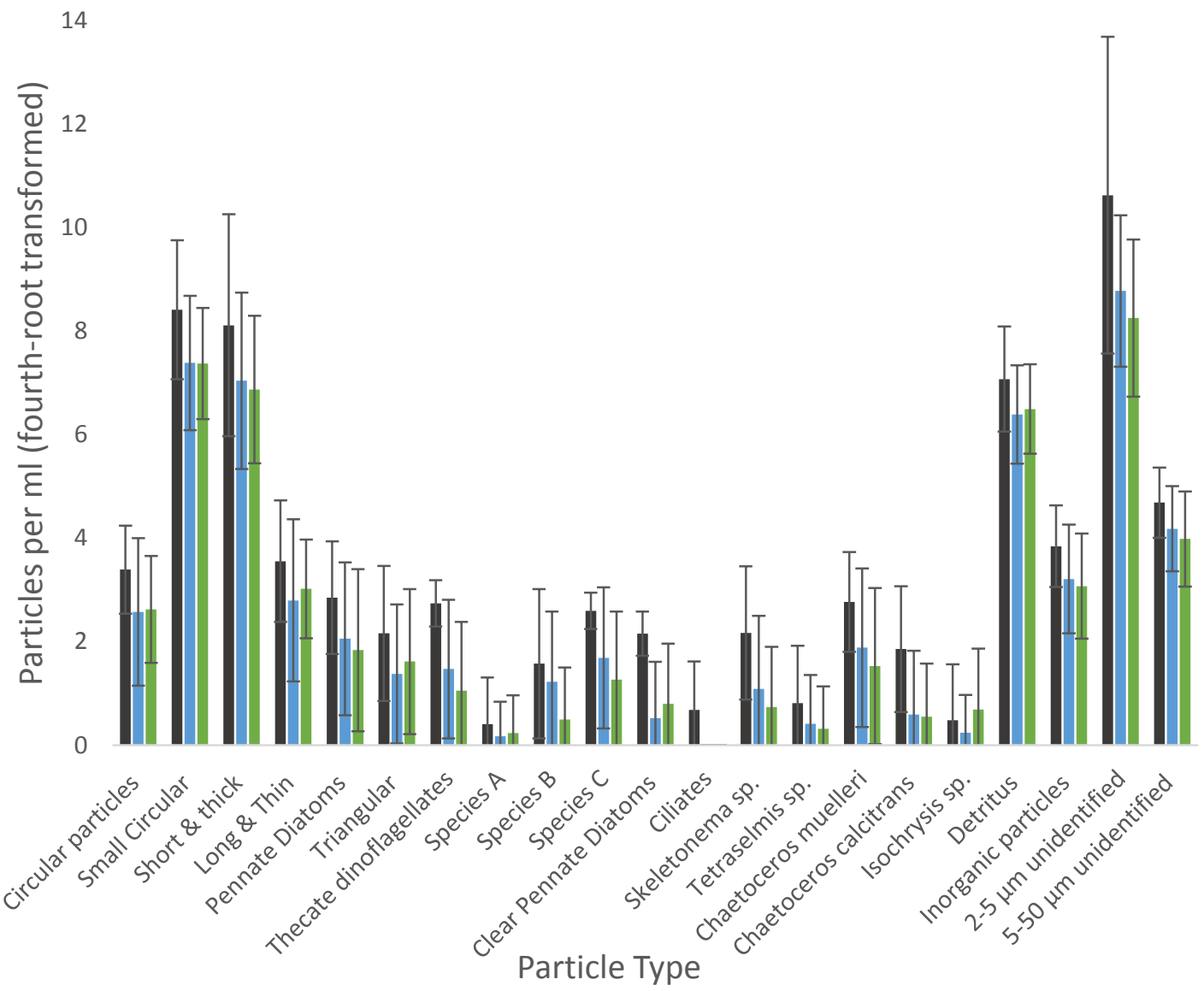

Figure 11. The number of particles per $\mathrm{ml}$ (fourth-root transformed) $\pm \mathrm{SD}$, of particles types recorded in Nelson during autumn. The blue bars are $M$. galloprovincialis, the green are $P$. canaliculus and the control is shown in black. 
In Nelson during winter the outflow water of the control chambers always had higher particle concentrations than the outflow of the experimental chamber that held either $M$. galloprovincialis or P. canaliculus (Figure 12). This shows feeding on all particle types by each species of mussels. Particle types that were selectively feed on by M. galloprovincialis (indicated by a significantly difference between the control chambers and the chambers holding mussels) were thecate dinoflagellates, ciliates and Skeletonema sp. (Table 8). The water from the outflow of chambers holding $P$. canaliculus had a significantly lower amount of particles than the control chambers of Species C, clear pennate diatoms, ciliates, $C$. calcitrans and interestingly inorganic particles (Table 8).

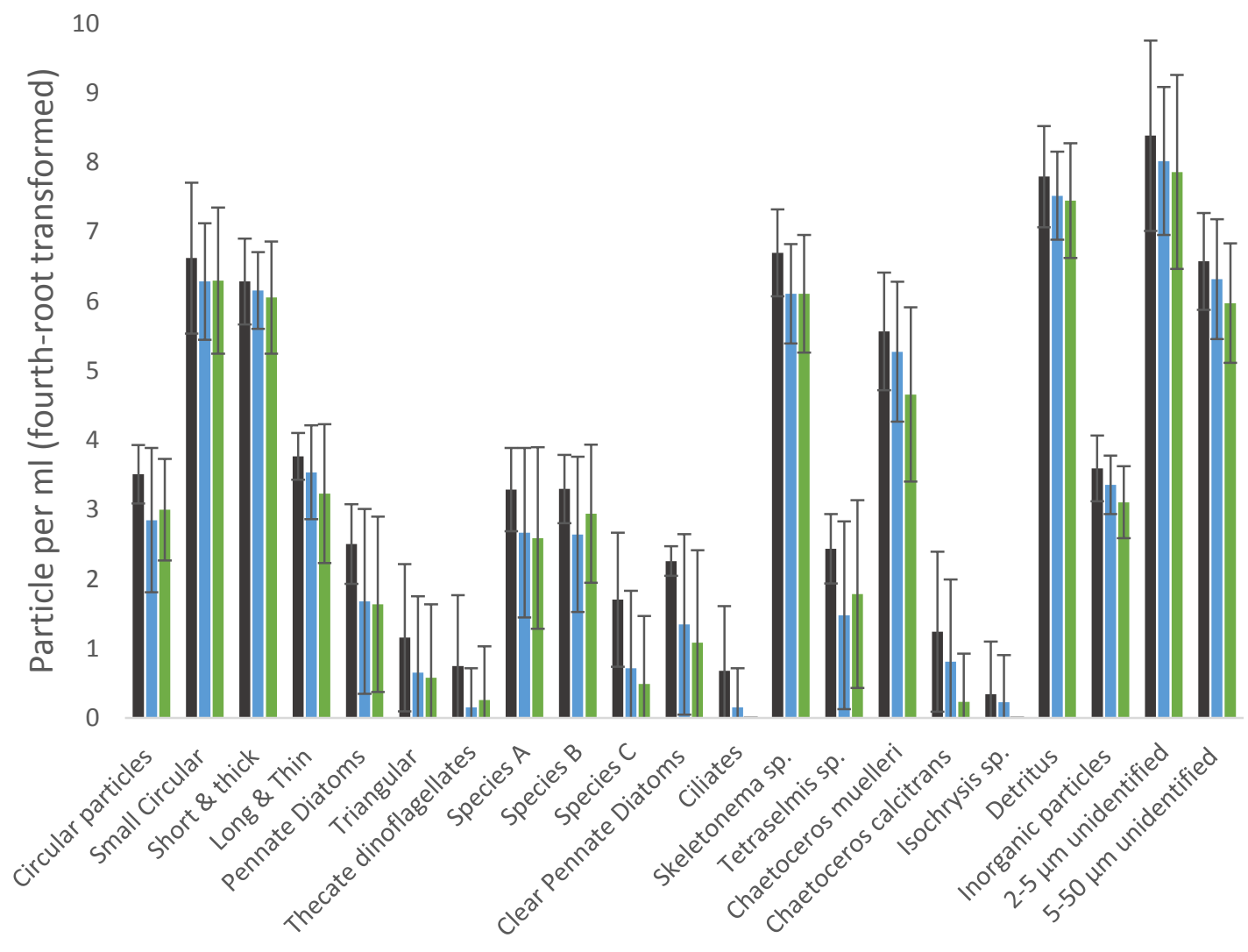

Particle Type

Figure 12. The number of particles per $\mathrm{ml}$ (fourth-root transformed) $\pm \mathrm{SD}$, of particles types recorded in Nelson during winter. The blue bars are $M$. galloprovincialis, the green are $P$. canaliculus and the control is shown in black. 
At both sites and in both seasons the concentrations of particle types were almost always higher in the outflow of the control chambers when compared to the experimental chambers holding mussels, although all chambers were supplied with the same sea water source during each experiment. This indicates that both species of mussels were feeding on all particle types. There were significant differences found in some particle types at each site and season (Tables 5-8) which suggests that mussels were preferentially selecting these particle types over the others. The type of particle selected varied between species with M. galloprovincialis generally preferentially selecting less particle types than $P$. canaliculus, and more particle types being selected when the mussels were fed on the enriched pond water at Nelson compared to when the mussels were fed on Cook Strait seawater at Island Bay. 


\section{Discussion}

Mussels are an important component in the structure and function of rocky intertidal communities and generally occupy the mid-tidal regions of the intertidal community in temperate regions around the world (Stephenson and Stephenson 1949). Mussels are strong competitors for spaces, are a food source for a number of species, transfer energy through benthic-pelagic coupling and are ecosystem engineers as they provide a habitat for other species to live in (Dahlhoff and Menge 1996, Ward and Shumway 2004, Strohmeier et al. 2012, Arribas et al. 2014). In Wellington Harbour mussels are present in dense beds and are important components of the structure and function of the intertidal community. Yet just kilometres away on the shores of the Cook Strait there is an almost complete absence of any mussel species. The reasons as to why mussels are absent has been studied from a number of different angles, but food limitations best explains the variation in community structure (Gardner 2000, Helson and Gardner 2007, Helson et al. 2007, Gardner 2008, 2013) and has been further investigated in this study.

\section{Environmental characteristics of Wellington Harbour and Cook Strait}

Significant differences were found in all environmental characteristics between Wellington Harbour and Cook Strait. Wellington Harbour had a higher concentration of total suspended sediment, chlorophyll $a$, turbidity and a warmer temperature. Island Bay had a higher salinity. Satellite and CTD data determined that Wellington Harbour was a much more productive habitat for mussels to inhabit compared to Cook Strait as it had a higher quantity and quality of seston. Wellington Harbour had an almost tenfold increase in the chlorophyll $a$ concentrations, a proxy for seston quality as it indicates the amount of phytoplankton present and a larger quantity of seston represented by turbidity.

All mean values recorded for the environmental variables are similar to previous studies comparing the Cook Strait and Wellington Harbour (Helson et al. 2007, Gardner 2013). And Cook Strait results are similar to early recordings of chlorophyll $a$ in the Cook Strait of an average of 0.25 to $0.75 \mu \mathrm{g} \mathrm{l}^{-1}$ (Bradford et al. 1986). The values recorded by the satellite for the Cook Strait falls within the average chlorophyll $a$ for Exclusive Economic Zone of New 
Zealand which was determined by Murphy et al. (2001) as between $0.26-0.46 \mathrm{mg} \mathrm{m}^{-3}$ (= $\mathrm{\mu g}$ $\left.\mathrm{I}^{-1}\right)$. This average was largely based on the oceanic waters, and considering the Cook Strait site was only $1 \mathrm{~km}$ off shore it is still quite low. The temperature showed seasonal variation at both locations with the warmer months occurring in summer. Chlorophyll $a$ and turbidity displayed seasonal variation in Wellington Harbour, with higher concentrations in the summer months and a separate peak in October.

The different hydrological conditions will play a role in the differences seen in the quality and quantity of seston between Wellington Harbour and Cook Strait (Gardner 2000, Helson 2001). Wellington Harbour is a semi-enclosed embayment with an average depth of $20 \mathrm{~m}$, it is thought to be well-mixed and is partially separated from the Cook Strait (Booth 1975). The Cook Strait is a fast-moving, exposed stretch of water sourced from the Tasman Sea (Helson 2001). The Hutt River flows into the northern end of Wellington Harbour and inputs a large amount of nutritious and particle-rich riparian water (Booth 1975). The riparian input from the Hutt River may be playing a role in the gradient observed in the satellite data. Both total suspended sediment and chlorophyll $a$ were highest inside the harbour and decreased with distance into the Cook Strait.

Spatial and seasonal variations in food and nutrient availability effects the physiology of the intertidal suspension feeders (Dahlhoff and Menge 1996). So water column variables are important to consider when looking at the available food supply for mussels (Riisgård et al. 2013). The chlorophyll $a$ concentrations recorded for Island Bay and Cook Strait are too low to allow mussels sufficient growth there. It has been determined that when $P$. canaliculus (of $1 \mathrm{~g}$ dry tissue weight) is fed on seston with a lower chlorophyll a concentration than $0.86 \pm$ $0.19 \mu \mathrm{g} \mathrm{I}^{-1}$ tissue wasting occurred (Hawkins et al. 1999). The Cook Strait is well below that threshold with an average chlorophyll $a$ of $0.39 \mu \mathrm{g} \mathrm{l}^{-1}( \pm 0.17)$ recorded by the CTD. The satellite data provided a slightly higher concentrations for Island Bay which was $1.54 \pm 0.53$ $\mu \mathrm{g}^{-1}$ and further out in the Cook Strait was $0.47 \pm 0.10 \mu \mathrm{m} \mathrm{I}^{-1}$.

It would have been beneficial to this study if the water samples collected from Wellington Harbour and Cook Strait had been processed using the FlowCAM to determine the species composition. As phytoplankton species composition in the Marlborough Sounds, which is situated just south of Cook Strait, have been shown to vary throughout the year with diatoms dominating most of the year except for spring when dinoflagellates dominated the species 
composition (Safi and Gibbs 2003). Little is known about the seasonal cycle of phytoplankton and inter-annual variability of the plankton in the Cook Strait (Bradford-Grieve and Stevens 2013), so having the species composition would have been very useful. The information on chlorophyll $a$ is beneficial to understanding the phytoplankton productivity though. The information gathered in this study adds to the information on confirming that mussels are almost absent on the shores of the Cook Strait due to food limitations and confirms the hypothesis that environmental variables that describe the seston quality and quantity are limited in the Cook Strait and are in greater concentrations in Wellington Harbour.

\section{Feeding experiments}

In Nelson Cawthron's enriched seawater ponds were expected to be a high quality comparison to Island Bay's (Cook Strait) low quality seawater. This held true for summer and winter for all seston characteristics, but when experiments were being conducted in autumn at Island Bay a storm occurred which increased the TPM, POM, PCOM and particle count. At Island Bay the TPM and POM were higher than previously recorded values the same location (Gardner 2000, 2002, Helson et al. 2007). Chlorophyll $a$ at Island Bay were higher than recorded by Helson et al. (2007). The TPM, POM, PCOM and chlorophyll $a$ were higher in Nelson and apart from in autumn were on average higher than Island Bay.

The chlorophyll a concentrations were low during each season at Island Bay, even in the storm in autumn the average concentration was only $0.44 \mathrm{\mu g} \mathrm{I}^{-1}$, which was higher than Helson et al. (2007) recorded at Island Bay, but lower than the values recorded in Nelson or during other studies. The values recorded in Nelson were similar to those of Ren and Ross (2005) who recorded values between $0.2-2.3 \mu \mathrm{g} \mathrm{I}^{-1}$ in the Marlborough Sounds. Gibbs and Vant (1997) recorded values of $3-6 \mathrm{~g} \mathrm{~g}^{-1}$ in winter also in the Marlborough Sounds. Ogilvie et al. (2000) found a large variation in chlorophyll $a$ concentrations in the Marlborough Sounds which ranged from $0.5 \mu \mathrm{g} \mathrm{I}^{-1}$ in summer to $5 \mu \mathrm{g} \mathrm{l}^{-1}$ in autumn-winter. The seston and water characteristics recorded in this study also display seasonal variation. Dahlhoff and Menge (1996) found a similar pattern as to Wellington Harbour and the Cook Strait on the coasts of Oregon. At Boiler Bay there is a low abundance of filter feeders while at Strawberry Hill there is a relatively high abundance. Phytoplankton abundance and productivity are higher at 
Strawberry Hill, and lower in Boiler Bay suggesting suspension feeders are present due to the higher food availability. A strong link was found between the seston availability and the mussel's physiological response.

PCOM has to be over $20 \%$ for mussels to be able to overcome metabolic faecal loss (which is energy lost from enzyme secretion to the gut and abrasion of cellular material from the gut passage) (Gardner and Thompson 2001) and to have a positive net energy balance. All PCOM recorded in Island Bay were higher than 20\%, and in Nelson the PCOM was always over 25\%, which suggests there was enough food available for mussel to survive on the shores of the Cook Strait. Each experiment was a week long and it is possible that the experimental dates coincided with higher PCOM that average, as the PCOM recorded are higher than previous studies which do suggest food limitations as an explanation for the absence of mussels (Gardner 2000, 2002, Helson et al. 2007).

Clearance rate (CR) is the main mechanism of energy acquisition (Hawkins et al. 1999, Gardner 2002), it can account for around 70\% of energy intake Bayne (1976). When mussels were held in Island Bay (fed on Cook Strait water) a higher standardised clearance rate (CRs) was found in each season compared to mussels supplied with enriched pond water in Nelson. CRs varied between the seasons, on average CRs was higher in summer and lowest during autumn. The CRs recorded for M. galloprovincialis and $P$. canaliculus were similar, on average in Nelson CRs was higher for M. galloprovincialis but in Island Bay $P$. canaliculus had a higher CRs on average. All CRs results were similar to previously recorded values of CRs recorded at Island Bay (Gardner 2000, 2002). But contrasted to Tam (2012) who recorded a much higher CRs during summer and winter at Island Bay for M. galloprovincialis (5.84 and $5.15 \mathrm{I} \mathrm{g}^{-1} \mathrm{~h}^{-1}$ respectively) and a lower CRs for $P$. canaliculus.

The CRs of both species was highest in seasons of low POM and PCOM. This differs to a number of studies that have found a higher CRs when the POM and PCOM was higher. For example when comparing mussel feeding in Wellington Harbour, which has a higher seston quality, to Island Bay (Cook Strait), which has a lower quality, the CRs was higher for both $M$. galloprovincialis and P. canaliculus (Gardner 2002, Helson and Gardner 2007, Tam 2012).

The absorption efficiency (AE) strongly depended on the quality of food supplied to the mussel (Gardner and Thompson 2001), because of this dependence AE can be an indicator of 
the food availability (Helson and Gardner 2007). AE varied between the different sites and season. The AE values recorded when mussels were held in Island Bay were lower than when mussels were held in Nelson for summer and winter, during autumn Island Bay had the highest $A E$ values. When each sites $A E$ was averaged across all season both were 0.26 . And although on average $A E$ values were all positives some negative values were recorded for individual species. Negative AE values were recorded in $8 \%$ of mussels in Island Bay and only $0.5 \%$ of mussels held in Nelson.

P. canaliculus had a higher AE in each experiment than M. galloprovincialis, except for summer in Nelson. This contrasts to Tam (2012) who found a higher AE for M. galloprovincialis than P. canaliculus. The recorded values in this study are lower than Tam (2012) for M. galloprovincialis but are higher for $P$. canaliculus during summer and winter at Island Bay. Gardner (2000) however found $P$. canaliculus to have higher AE values than $M$. galloprovincialis their recorded AE values were lower than those recorded during this study at Island Bay.

The $A E$ varied at each site during each season and was highest in autumn when POM and PCOM had the highest concentrations. Interestingly the highest AE values were recorded when CRs was lowest. An inverse relationship between CR and AE has been found for $M$. edulis by Bayne et al. (1976) (as cited in Gardner (2002)), who suggested that the reduction in CR may have been a physiological compensation to maintain or increase AE. But in Gardner (2002) study found no evidence of this relationship in M. galloprovincialis, $P$. canaliculus or Aulacomya maoriana, nor did Gardner and Thompson (2001) for P. canaliculus. AE has been found to vary not only due to different seston qualities, but also when mussels are feed different types of algal species due to the digestibility of different species. For example diatoms may be harder to digest due to their silica walls than other phytoplankton species (Filgueira et al. 2010).

The net energy balance (NEB) is the amount of energy available to an individual after energy acquisition and expenditures have been accounted for, a positive NEB is an indicator of growth while a negative NEB indicates that the energy cost of living in that environment are too high to be sustained by the food available (Gardner and Thompson 2001). All mean NEB were positive in this study. P. canaliculus had a higher NEB value than M. galloprovincialis on average. The highest NEB were recorded during autumn at Island Bay, which coincided 
with a storm event. In summer and winter NEB was highest for the mussels being fed from Cawthron's enriched pond water supply in Nelson. The NEB values recorded mirror the AE values. Some negative values were recorded for individuals but on average the NEB was positive which indicates mussels were obtaining enough energy for growth.

These results contrast somewhat to Gardner (2000) who found negative NEB for $M$. galloprovincialis and $P$. canaliculus during summer at Island Bay and much lower values in winter. The NEB values recorded are more similar to those reported by Tam (2012), but different in that they found a much higher NEB for M. galloprovincialis than $P$. canaliculus in summer and winter when the mussels were held in Island Bay.

The net energy balance is strongly linked to the quality of diet (chlorophyll $a, \mathrm{POM}$ and PCOM) (Bayne et al. 1987, Gardner and Thompson 2001, Gardner 2002), and NEB values recorded in this study were generally higher when POM and PCOM were high. The NEB recorded during these experiments are slightly over-estimated as the energy loss of ammonium excretion was not included in the calculation.

Mussels have the ability to store energy and utilise this stored energy in times of low food supply. For example Bayne and Widdows (1978) discovered that Mytilus edulis could survive up to four months of negative NEB during the winter period by relying on stored energy. It could be possible then, that the mussels that were transplanted to Island Bay for the experiment are utilising stored energy to enhance their ability to gain energy from the low quality environment. It would be of interest to run longer term studies on mussels held in Cook Strait conditions and see how they respond after a longer timeframe.

The environmental variables can modify the behaviour of the organism, resulting in a physiological adjustment which can have an effect on the abundance and distribution of that species. This can then flow-on to effect the community structure (Dahlhoff and Menge 1996). The feeding responses recorded during this experiment only partially support the hypothesis that low food quality is limiting the presence of mussels on the shores of the Cook Strait. As the food quality characteristics such as POM, PCOM and chlorophyll $a$ were low but not low enough to starve the mussels year round. AE and NEB were on average always positive which indicates that mussels were gaining enough energy in Island Bay to live during each season tested, although around $10 \%$ of NEB recorded at Island Bay were negative. 


\section{Analysis of particle properties using FlowCAM}

The preferential selection of certain types of particles by different species mussels has been studied for almost a hundred years (Allen 1921). Recently studies have focussed on how the seston composition affects the growth and energetics of mussels rather than just looking at the phytoplankton biomass as a whole (Ward and Shumway 2004, Ren et al. 2006, Safi and Hayden 2010). In the present study, it was hypothesised that there would be no difference in particle properties selected by either $M$. galloprovincialis or P. canaliculus, but that there would be preferential selection of different types of particles when fed seawater from the Cook Strait and from the enriched pond water in Nelson. There was evidence for preferential selection of different particle types by both $M$. galloprovincialis and $P$. canaliculus at Island Bay and Nelson. But there was only difference in particle properties (such as compactness, roughness, etc.) for mussels being fed from the enriched ponds.

In the experimental chambers for both $M$. galloprovincialis and $P$. canaliculus the particle properties in the outflow water were different to the outflow of the control chambers when being feed on the enriched pond water in Nelson. Unfortunately each particle property was not individually investigated which would have been interesting for the mussels held in Nelson, as it may have provided insight into what types of particle properties the mussels were actually selecting for example volume, roughness etc. From the seston characteristics recorded in the feeding experiments, the overall particle count $\mathrm{ml}^{-1}$ was higher in the water in Nelson than in Island Bay during autumn and winter. It is possible that the increase in the concentration of particles let the mussels selectively feed based on certain properties rather than just consuming as much food as possible. The CRs values were also lower for mussels held in Nelson which could indicate that they did not need to filter as much water to gain the energy needed.

When the total seston composition (which was comprised of all particle types) from the control chamber was compared to the experimental chambers holding either $M$. galloprovincialis or $P$. canaliculus a significant difference was found, but there was no difference between the two species in the overall seston composition that was being ingested. All particle types had a higher concentration in the control chamber compared to 
the chambers that had mussels feeding in them, which was expected and shows that mussels were feeding.

It was interesting to see how $M$. galloprovincialis and $P$. canaliculus fed the two sites during autumn and winter when looking at the individual particle types and what particles the mussels were selectively feeding on. When the mussels were held in Island Bay during autumn both species of mussels had the highest NEB recorded as well as the highest seston quality in terms of POM and PCOM. Overall both species selected less particle types during this time. P. canaliculus only selectively fed on circular particles, and M. galloprovincialis selectively fed on the triangular shaped particles and the long and thin particles. Compared to autumn, mussels held during winter at Island Bay displayed a wider range of selective feeding. During this time the lowest NEB were recorded for both species.

Detritus was being selected by both species in Island Bay during winter which was not recorded during any other experiment. It is possible that the mussels were utilising detritus as a food source when the quality of the seston was low; previous research has found detritus to be an important component of mussels diets (Navarro et al. 1996). Ren and Ross (2005) noted the need for further studies on the importance of detritus to the growth of mussels. The hypothesis that mussels only selectively feed on detritus when the seston quality was low suggests that mussels may utilise this food source more when higher quality particles are unavailable.

At Island Bay during winter more particle type selection occurred than in autumn. The poor quality of the seston (POM and PCOM) may have caused the mussels to respond by increasing their CRs and selecting a wider range of particles than they would in higher quality condition, which they were exposed to in Island Bay during autumn. It has previously been found that mussels increase filtration rate and reject low quality particles to increase to increase the maximum amount of energy (Bayne et al. 1993).

When the mussels were held at Nelson during autumn they showed the greatest range of preferential selection with both mussel species selecting similar types of particles. $P$. canaliculus selected a larger range of particles than M. galloprovincialis in autumn and winter at Nelson as well. Both mussel species selected less particle types in winter than in autumn. 
P. canaliculus can alter feeding behaviour in response to different food supplies (Hatton et al. 2005). This was seen in this experiment for $P$. canaliculus and M. galloprovincialis as they both changed the particles they were preferentially selecting between sites and seasons. The plasticity of mussel feeding responses to naturally varying levels of seston quality helps to maintain positive growth (Bayne et al. 1987) and it is probable that the plasticity seen in the selection of particles in the present set of experiments is also a response to maintain a positive NEB.

The type of particles that were selected for was a function of mussel species, season and site. There were some particle types that were selected for by both mussel species, such as ciliates, but particle selection generally varied between the species. This pattern was more noticeable at Island Bay than at Nelson. When feeding on the enriched pond water at Cawthron in Nelson M. galloprovincialis often selected the same particles as $P$. canaliculus. In total P. canaliculus preferentially selected a wider range of particles than $M$. galloprovincialis which may have explained by the fact that $P$. canaliculus had a higher AE and NEB overall when both species were fed from the same water supply. Food limitations may be different for the different types of species (Bayne et al. 1988); this may be true for M. galloprovincialis and $P$. canaliculus as they were, on average, selecting different particles to each other.

A number of studies have been conducted investigating what $P$. canaliculus preferentially feeds on, as they are a very important aquaculture species in New Zealand. For example Zeldis et al. (2004) and Safi and Hayden (2010) both found that $P$. canaliculus preferentially selected ciliates, which was also found in this study when ciliates were present. It was thought that ciliates were selected as they have a weak swimming ability and a high nutritional content (Zeldis et al. 2004, Safi and Hayden 2010). Safi and Hayden (2010) found the P. canaliculus preferred flagellated particles including dinoflagellates but grazed on most species over $2 \mu \mathrm{m}$. Dinoflagellates have a higher carbon ratio and nutritional value than diatoms (Menden-Deuer and Lessard 2000), and a higher assimilation efficiency than flagellates or diatom for $P$. canaliculus (Ren et al. 2006). James et al. (2001) however found little difference in the phytoplankton composition in the water that passed through the controls to the water that $P$. canaliculus had fed on and suggested that $P$. canaliculus are non-selective at phytoplankton groups level when sorting first occurs pre-ingestion. James et al. (2001) 
investigated particles in the size range 5-100 $\mu \mathrm{m}$. M. galloprovincialis have been also been found to preferentially select dinoflagellates over diatoms (Sidari et al. 1998).

Selective grazing could significantly impact phytoplankton species composition, so there is a need to understand what types of particles mussels are selecting or rejecting as it will provide a greater understanding of the top-down role mussels have on the phytoplankton community and provide a greater insight into benthic-pelagic coupling. This is especially important for $P$. canaliculus as it is a heavily farmed aquaculture species in New Zealand.

Mussels need to be able to select and capture a food source to occupy any given location given that they are sessile and cannot move in search of food (Safi and Hayden 2010). In this study it has been found that both M. galloprovincialis and $P$. canaliculus can select and feed on particles when fed low quality seawater from the Cook Strait. But the amount of particles they preferentially select is lower than when they are fed a high quality food source (such as seawater from the enriched ponds in Nelson). It is possible that although this study captured a time when mussels were able to select certain types of particles and maintain a positive NEB that there are other times of the year when they cannot, or are forced to select lower quality particles such as the detritus which was seen during winter. What was not quantified in this study was whether the particles selected were nutritionally more beneficial than the other, although it was assumed so, given that they were selected for.

In future studies it would be interesting to have more information on the nutritional qualities of the particles being selected for and to analyse the pseudofaeces that were produced. Only some individuals produced pseudofaeces which may influence the results as they have not selected for this particles but have actually rejected them in the pseudofaeces. It would be important in future studies to also analyse the pseudofaeces to see what particles have been rejected as Baker et al. (1998) found the zebra mussel (Dressena polymorpha) were rejecting diatoms in their pseudofaeces.

\section{Conclusions}

The PCOM values recorded in this study are large enough to sustain growth in mussels which is shown by the positive average net energy balance values. But chlorophyll $a$ concentrations 
recorded in Cook Strait during the feeding experiments and yearly CTD data never exceeded the concentration of $0.86 \pm 0.19 \mu \mathrm{g} \mathrm{I}^{-1}$ which is the minimum chlorophyll $a$ needed for $P$. canaliculus to not experience tissue wastage (Hawkins et al. 1999) and ultimately death. While values in recorded in Wellington Harbour and during the experiments in Nelson were higher, high enough to allow mussels to survive in these locations.

Mussels can alter their feeding behaviour to maintain positive growth under varying naturally occurring seston levels. Plasticity in the CRs, AE, NEB and particle selection by $P$. canaliculus and $M$. galloprovincialis were recorded during each season and between the varying seston qualities provided at each site, this plasticity resulted in positive net energy balance in each experiment. The environmental variables recorded suggest the bottom-up regulation of food limitations is causing the almost complete absence of any species of mussels on Cook Strait shore, yet the physiological behaviour and responses suggests that mussels should be able to survive there under the conditions recorded during this study. So only partial acceptance of the hypothesis that food limitations are causing the absence of mussels on the shores of the Cook Strait can occur, and more work is needed on understanding how mussels respond over a longer timeframe when being fed on Cook Strait seawater.

To the best of my knowledge this study is the first time in New Zealand that the FlowCAM has been used to investigate particle selection in mussels. Particle selection had not been examined for any species of mussel under the natural seston variability on the Cook Strait, and this study has provided insight into how mussels preferentially select particles when subjected to this low seston quality. This study also provides interesting information on interspecific particle selection when subjected to naturally occurring seston conditions for $M$. galloprovincialis and P. canaliculus.

The information obtained during this study is valuable in understanding how mussels respond to the conditions in the Cook Strait. This study builds on the previous literature on how low food availability is causing an almost complete absence of mussels on the shores of the Cook Strait, and provides new information on how Perna canaliculus and Mytilus galloprovincialis selectively feed on particles when subjected to these seston conditions. 


\section{References}

Allen, W. R. 1921. Studies of the biology of freshwater mussels The Biological Bulletin 40:210-241.

Álvarez, E., Á. López-Urrutia, E. Nogueira, and S. Fraga. 2011. How to effectively sample the plankton size spectrum? A case study using FlowCAM. Journal of plankton research 33:1119-1133.

Álvarez, E., M. Moyano, Á. López-Urrutia, E. Nogueira, and R. Scharek. 2013. Routine determination of plankton community composition and size structure: a comparison between FlowCAM and light microscopy. Journal of plankton research:fbt069.

Arribas, L. P., L. Donnarumma, M. G. Palomo, and R. A. Scrosati. 2014. Intertidal mussels as ecosystem engineers: their associated invertebrate biodiversity under contrasting wave exposures. Marine Biodiversity 44:203-211.

Baker, S. M., J. S. Levinton, J. P. Kurdziel, and S. E. Shumway. 1998. Selective feeding and biodeposition by zebra mussels and their relation to changes in phytoplankton composition and seston load. Journal of Shellfish Research 17:1207-1214.

Bayne, B., A. Hawkins, and E. Navarro. 1987. Feeding and digestion by the mussel Mytilus edulis L.(Bivalvia: Mollusca) in mixtures of silt and algal cells at low concentrations. Journal of Experimental Marine Biology and Ecology 111:1-22.

Bayne, B., A. Hawkins, and E. Navarro. 1988. Feeding and digestion in suspension-feeding bivalve molluscs: the relevance of physiological compensations. American zoologist 28:147-159.

Bayne, B., J. Iglesias, A. Hawkins, E. Navarro, M. Heral, and J.-M. Deslous-Paoli. 1993. Feeding behaviour of the mussel, Mytilus edulis: responses to variations in quantity and organic content of the seston. Journal of the Marine Biological Association of the United Kingdom 73:813-829.

Bayne, B., R. Thompson, and J. Widdows. 1976. Physiology 1. Pages 121-206 in B. Bayne, editor. Marine Mussels, Their Ecology and Physiology. Cambridge Scientific Press

Bayne, B., and J. Widdows. 1978. The physiological ecology of two populations of Mytilus edulis Oecologia 37:137-162.

Bird, C. E., E. C. Franklin, C. M. Smith, and R. J. Toonen. 2013. Between tide and wave marks: a unifying model of physical zonation on littoral shores. PeerJ 1:e154.

Booth, J. D. 1975. Seasonal and tidal variations in the hydrology of Wellington Harbour. New Zealand Journal of Marine and Freshwater Research 9:333-354.

Bowman, M., A. Kibblewhite, R. Murtagh, S. Chiswell, and B. Sanderson. 1983. Circulation and mixing in greater Cook Strait, New Zealand. Oceanologica acta 6:383-391.

Bracken, M. E. S., B. A. Menge, M. M. Foley, C. J. B. Sorte, J. Lubchenco, and D. R. Schiel. 2012. Mussel selectivity for high-quality food drives carbon inputs into open-coast intertidal ecosystems. Marine Ecology Progress Series 459:53-62.

Bradford-Grieve, J., and C. Stevens. 2013. Zooplankton and the processes supporting them in Greater Western Cook Strait. NIWA Client Report No: WLG2013-9.

Bradford, J., P. Lapennas, R. Murtagh, F. Chang, and V. Wilkinson. 1986. Factors controlling summer phytoplankton production in greater Cook Strait, New Zealand. New Zealand Journal of Marine and Freshwater Research 20:253-279.

Connell, J. H. 1961. Effects of competition, predation by Thais lapillus, and other factors on natural populations of the barnacle Balanus balanoides. Ecological Monographs 31:61-104.

Connell, J. H. 1972. Community interactions on marine rocky intertidal shores. Annual Review of Ecology and Systematics 3:169-192.

Conover, R. J. 1966. Assimilation of Organic Matter by Zooplankton. Limnology and Oceanography 11:338-\&. 
Dahlhoff, E., and B. Menge. 1996. Influence of phytoplankton concentration and wave exposure on the ecophysiology of Mytilus californianus. Marine ecology progress series. Oldendorf 14:97107.

Demello, R., and N. E. Phillips. 2011. Variation in mussel and barnacle recruitment parallels a shift in intertidal community structure in the Cook Strait region of New Zealand. Marine and Freshwater Research 62:1221-1229.

Filgueira, R., M. J. Fernández-Reiriz, and U. Labarta. 2010. Clearance rate of the mussel Mytilus galloprovincialis. II. Response to uncorrelated seston variables (quantity, quality, and chlorophyll content). Ciencias Marinas 36:15-28.

FlowCAM. 2011. FlowCAM Manual in B. Spaulding, editor. VisualSpreadsheet ${ }^{\circledR}$ 3.0, Portable, Open Benchtop,Benchtop Models. Fluid Imagine Technologies, Inc. , USA.

García-Muñoz, C., L. M. Lubián, C. M. García, Á. Marrero-Díaz, P. Sangrà, and M. Vernet. 2013. A mesoscale study of phytoplankton assemblages around the South Shetland Islands (Antarctica). Polar biology 36:1107-1123.

Gardner, J. P. A. 2000. Where are the mussels on Cook Strait (New Zealand) shores? Low seston quality as a possible factor limiting multi-species distributions. Marine Ecology Progress Series 194:123-132.

Gardner, J. P. A. 2002. Effects of seston variability on the clearance rate and absorption efficiency of the mussels Aulacomya maoriana, Mytilus galloprovincialis and Perna canaliculus from New Zealand. Journal of Experimental Marine Biology and Ecology 268:83-101.

Gardner, J. P. A. 2008. Where are the mussels on Wellington's South Coast?in J. P. A. Gardner, editor. The Taputeranga Marine Reserve. First Edition Publishers, Wellington.

Gardner, J. P. A. 2013. Bottom-up control of temperate rocky intertidal community structure: evidence from a transplant experiment. Marine Ecology Progress Series 491:137-151.

Gardner, J. P. A., and R. J. Thompson. 2001. Naturally low seston concentration and the net energy balance of the greenshell mussel (Perna canaliculus) at Island Bay, Cook Strait, New Zealand. New Zealand Journal of Marine and Freshwater Research 35:457-468.

Gibbs, M., and W. Vant. 1997. Seasonal changes in factors controlling phytoplankton growth in Beatrix Bay, New Zealand. New Zealand Journal of Marine and Freshwater Research 31:237248.

Gili, J.-M., and R. Coma. 1998. Benthic suspension feeders: their paramount role in littoral marine food webs. Trends in Ecology \& Evolution 13:316-321.

Hatton, S., B. Hayden, and M. James. 2005. The effects of food concentration and quality on the feeding rates of three size classes of the GreenshellTM mussel, Perna canaliculus. Hydrobiologia 548:23-32.

Hawkins, A., M. James, R. Hickman, S. Hatton, and M. Weatherhead. 1999. Modelling of suspensionfeeding and growth in the green-lipped mussel Perna canaliculus exposed to natural and experimental variations of seston availability in the Marlborough Sounds, New Zealand. Marine Ecology Progress Series 191:217-232.

Helson, J. 2001. An investigation into the absence of mussels (Perna canaliculus, Aulacomya maoriana and Mytilus galloprovincialis) from the south coast of Wellington, New Zealand. $\mathrm{PhD}$ thesis Victoria University of Wellington Victoria University of Wellington

Helson, J. G., and J. P. A. Gardner. 2004. Contrasting patterns of mussel abundance at neighbouring sites: does recruitment limitation explain the absence of mussels on Cook Strait (New Zealand) shores? Journal of Experimental Marine Biology and Ecology 312:285-298.

Helson, J. G., and J. P. A. Gardner. 2007. Variation in scope for growth: a test of food limitation among intertidal mussels. Hydrobiologia 586:373-392.

Helson, J. G., S. Pledger, and J. P. A. Gardner. 2007. Does differential particulate food supply explain the presence of mussels in Wellington Harbour (New Zealand) and their absence on neighbouring Cook Strait shores? Estuarine Coastal and Shelf Science 72:223-234. 
James, M., M. Weatherhead, and A. Ross. 2001. Size-specific clearance, excretion, and respiration rates, and phytoplankton selectivity for the mussel Perna canaliculus at low levels of natural food. New Zealand Journal of Marine and Freshwater Research 35:73-86.

Maar, M., T. G. Nielsen, K. Bolding, H. Burchard, and A. Visser. 2007. Grazing effects of blue mussel Mytilus edulis on the pelagic food web under different turbulence conditions. Marine Ecology Progress Series 339:199-213.

Mackenzie, A., H. Kaspar, and P. Gillespie. 1986. Some observations on phytoplankton species composition, biomass, and productivity in Kenepuru Sound, New Zealand, 1982-83. New Zealand Journal of Marine and Freshwater Research 20:397-405.

McQuaid, C., and T. L. Lindsay. 2000. Effect of wave exposure on growth and mortality rates of the mussel Perna perna: bottom up regulation of intertidal populations. Marine Ecology Progress Series 206:147-154.

McQuaid, C., and T. L. Lindsay. 2007. Wave exposure effects on population structure and recruitment in the mussel Perna perna suggest regulation primarily through availability of recruits and food, not space. Marine Biology 151:2123-2131.

Menden-Deuer, S., and E. J. Lessard. 2000. Carbon to volume relationships for dinoflagellates, diatoms, and other protist plankton. Limnology and Oceanography 45:569-579.

Menge, B. A. 2000. Top-down and bottom-up community regulation in marine rocky intertidal habitats. Journal of Experimental Marine Biology and Ecology 250:257-289.

Menge, B. A., and J. P. Sutherland. 1987. Community regulation: variation in disturbance, competition, and predation in relation to environmental stress and recruitment. American Naturalist:730-757.

Murphy, R., M. Pinkerton, K. Richardson, J. Bradford-Grieve, and P. Boyd. 2001. Phytoplankton distributions around New Zealand derived from SeaWiFS remotely-sensed ocean colour data. New Zealand Journal of Marine and Freshwater Research 35:343-362.

Navarro, E., J. Iglesias, A. P. Camacho, and U. Labarta. 1996. The effect of diets of phytoplankton and suspended bottom material on feeding and absorption of raft mussels (Mytilus galloprovincialis Lmk). Journal of Experimental Marine Biology and Ecology 198:175-189.

Ogilvie, S. C., A. H. Ross, and D. R. Schiel. 2000. Phytoplankton biomass associated with mussel farms in Beatrix Bay, New Zealand. Aquaculture 181:71-80.

Paine, R. T. 1966. Food web complexity and species diversity. American Naturalist:65-75.

Paine, R. T. 1971. A short-term experimental investigation of resource partitioning in a New Zealand rocky intertidal habitat. Ecology:1096-1106.

Phillips, N. E., and E. Hutchison. 2008. Grazer effects on algal assemblages and mussel recruitment in two different mid-intertidal communities in the Cook Strait, New Zealand. New Zealand Journal of Marine and Freshwater Research 42:297-306.

Phillips, N. E., A. R. Wood, and J. S. Hamilton. 2008. Molecular species identification of morphologically similar mussel larvae reveals unexpected discrepancy between relative abundance of adults and settlers. Journal of Experimental Marine Biology and Ecology 362:90-94.

Ren, J. S., and A. H. Ross. 2005. Environmental influence on mussel growth: A dynamic energy budget model and its application to the greenshell mussel Perna canaliculus. Ecological modelling 189:347-362.

Ren, J. S., A. H. Ross, and B. J. Hayden. 2006. Comparison of assimilation efficiency on diets of nine phytoplankton species of the greenshell mussel Perna canaliculus. Journal of Shellfish Research 25:887-892.

Riisgård, H. U., P. P. Egede, and I. Barreiro Saavedra. 2011. Feeding behaviour of the mussel, Mytilus edulis: new observations, with a minireview of current knowledge. Journal of Marine Biology 2011. 
Riisgård, H. U., D. Pleissner, K. Lundgreen, and P. S. Larsen. 2013. Growth of mussels Mytilus edulis at algal (Rhodomonas salina) concentrations below and above saturation levels for reduced filtration rate. Marine Biology Research 9:1005-1017.

Safi, K. A., and M. M. Gibbs. 2003. Importance of different size classes of phytoplankton in Beatrix Bay, Marlborough Sounds, New Zealand, and the potential implications for the aquaculture of the mussel, Perna canaliculus. New Zealand Journal of Marine and Freshwater Research 37:267-272.

Safi, K. A., and B. Hayden. 2010. Differential grazing on natural planktonic populations by the mussel Perna canaliculus. Aquatic Biology 11:113-125.

Safi, K. A., J. E. Hewitt, and S. G. Talman. 2007. The effect of high inorganic seston loads on prey selection by the suspension-feeding bivalve, Atrina zelandica. Journal of Experimental Marine Biology and Ecology 344:136-148.

Shumway, S. E., T. L. Cucci, R. C. Newell, and C. M. Yentsch. 1985. Particle selection, ingestion, and absorption in filter-feeding bivalves. Journal of Experimental Marine Biology and Ecology 91:77-92.

Sidari, L., P. Nichetto, S. Cok, S. Sosa, A. Tubaro, G. Honsell, and R. Della Loggia. 1998. Phytoplankton selection by mussels, and diarrhetic shellfish poisoning. Marine Biology 131:103-111.

Sieracki, C. K., M. E. Sieracki, and C. S. Yentsch. 1998. An imaging-in-flow system for automated analysis of marine microplankton. Marine Ecology Progress Series 168:285-296.

Stephenson, T., and A. Stephenson. 1949. The universal features of zonation between tide-marks on rocky coasts. The Journal of Ecology 37:289-305.

Strohmeier, T., $\varnothing$. Strand, M. Alunno-Bruscia, A. Duinker, and P. J. Cranford. 2012. Variability in particle retention efficiency by the mussel Mytilus edulis. Journal of Experimental Marine Biology and Ecology 412:96-102.

Tam, J. C. 2012. Intertidal community differences between the Cook Strait and Wellington Harbour. $\mathrm{PhD}$ thesis Victoria University of Wellington, Victoria University of Wellington.

Underwood, A. J. 2000. Experimental ecology of rocky intertidal habitats: what are we learning? Journal of Experimental Marine Biology and Ecology 250:51-76.

Wang, W.-X., and N. S. Fisher. 1996. Assimilation of trace elements and carbon by the mussel Mytilus edulis: Effects of food composition. Limnology and Oceanography 4:I.

Ward, E. J., L. Sanford, R. Newell, and B. MacDonald. 1998. A new explanation of particle capture in suspension-feeding bivalve molluscs. OCEANOGRAPHY 43.

Ward, E. J., and S. E. Shumway. 2004. Separating the grain from the chaff: particle selection in suspension-and deposit-feeding bivalves. Journal of Experimental Marine Biology and Ecology 300:83-130.

Widdows, J., and D. Johnson. 1988. Physiological energetics of Mytilus edulis: scope for growth. Marine Ecology Progress Series 46:113-121.

Zarauz, L., X. Irigoien, and J. A. Fernandes. 2009. Changes in plankton size structure and composition, during the generation of a phytoplankton bloom, in the central Cantabrian sea. Journal of plankton research 31:193-207.

Zeldis, J., K. Robinson, A. Ross, and B. Hayden. 2004. First observations of predation by New Zealand Greenshell mussels Perna canaliculus on zooplankton. Journal of Experimental Marine Biology and Ecology 311:287-299. 


\section{Appendices}

Appendix A1. Mean ( \pm SD) chlorophyll $a$ concentrations $\mu \mathrm{g}^{l^{-1}}$. Monthly averages are based on data from 2002 - 2014.

\begin{tabular}{|c|c|c|c|c|}
\hline Month & $\begin{array}{c}\text { Matiu/Somes } \\
\text { Island }\end{array}$ & Scorching Bay & Island Bay & Cook Strait \\
\hline \multirow{2}{*}{ January } & 4.36 & 3.12 & 0.71 & 0.51 \\
\hline & (3.18) & (3.18) & (3.18) & (3.18) \\
\hline \multirow[t]{2}{*}{ February } & 4.79 & 5.22 & 1.23 & 0.59 \\
\hline & (3.65) & (3.65) & (3.65) & (3.65) \\
\hline \multirow[t]{2}{*}{ March } & 4.54 & 5.83 & 1.30 & 0.54 \\
\hline & (3.65) & (3.64) & (3.64) & (3.64) \\
\hline \multirow[t]{2}{*}{ April } & 6.57 & 5.29 & 1.78 & 0.46 \\
\hline & (5.99) & (5.99) & (5.99) & (5.99) \\
\hline \multirow[t]{2}{*}{ May } & 5.76 & 8.34 & 2.21 & 0.50 \\
\hline & $(5.38)$ & (5.38) & (5.38) & (5.38) \\
\hline \multirow[t]{2}{*}{ June } & 6.37 & 5.83 & 2.33 & 0.31 \\
\hline & (5.96) & (5.96) & (5.96) & (5.96) \\
\hline \multirow{2}{*}{ July } & 6.05 & 7.22 & 2.24 & 0.39 \\
\hline & (3.95) & (5.96) & $(1.73)$ & $(0.33)$ \\
\hline \multirow[t]{2}{*}{ August } & 6.33 & 4.24 & 1.89 & 0.39 \\
\hline & (5.03) & $(2.85)$ & $(2.34)$ & $(0.33)$ \\
\hline \multirow[t]{2}{*}{ September } & 3.76 & 5.87 & 1.25 & 0.37 \\
\hline & $(2.73)$ & $(4.37)$ & (1.04) & $(0.13)$ \\
\hline \multirow[t]{2}{*}{ October } & 7.06 & 7.49 & 1.68 & 0.56 \\
\hline & $(6.03)$ & (6.66) & $(1.92)$ & (0.49) \\
\hline \multirow[t]{2}{*}{ November } & 4.35 & 5.57 & 0.93 & 0.66 \\
\hline & $(3.74)$ & $(5.00)$ & $(0.79)$ & $(0.50)$ \\
\hline \multirow[t]{2}{*}{ December } & 4.33 & 6.39 & 0.97 & 0.36 \\
\hline & $(3.70)$ & (5.13) & (1.14) & $(0.13)$ \\
\hline
\end{tabular}


Appendix A2. Mean ( $\pm S D$ ) total suspended sediment $\mathrm{mg} \mathrm{l}^{-1}$. Monthly averages are based on data from $2002-2014$.

\begin{tabular}{|c|c|c|c|c|}
\hline Month & $\begin{array}{l}\text { Matiu/Somes } \\
\text { Island }\end{array}$ & Scorching Bay & Island Bay & Cook Strait \\
\hline \multirow{2}{*}{ January } & 1.72 & 1.72 & 0.67 & 0.51 \\
\hline & $(0.55)$ & $(0.37)$ & $(0.22)$ & $(0.08)$ \\
\hline \multirow[t]{2}{*}{ February } & 1.34 & 1.81 & 0.88 & 0.49 \\
\hline & $(0.33)$ & $(0.91)$ & $(0.40)$ & $(0.12)$ \\
\hline \multirow[t]{2}{*}{ March } & 1.50 & 1.35 & 0.79 & 0.52 \\
\hline & $(0.60)$ & (0.39) & $(0.18)$ & $(0.11)$ \\
\hline \multirow[t]{2}{*}{ April } & 1.26 & 1.19 & 0.97 & 0.55 \\
\hline & $(0.57)$ & $(0.24)$ & $(0.54)$ & $(0.04)$ \\
\hline \multirow[t]{2}{*}{ May } & 2.20 & 1.44 & 0.74 & 0.58 \\
\hline & $(2.11)$ & $(0.30)$ & $(0.22)$ & $(0.10)$ \\
\hline \multirow[t]{2}{*}{ June } & 1.92 & 1.45 & 1.47 & 0.83 \\
\hline & (1.22) & $(0.37)$ & $(0.61)$ & $(0.16)$ \\
\hline \multirow{2}{*}{ July } & 2.12 & 2.06 & 1.12 & 0.87 \\
\hline & $(0.81)$ & $(0.96)$ & $(0.50)$ & (0.19) \\
\hline \multirow[t]{2}{*}{ August } & 1.45 & 1.25 & 1.16 & 0.8 \\
\hline & (1.07) & $(0.70)$ & $(0.72)$ & $(0.26)$ \\
\hline \multirow[t]{2}{*}{ September } & 1.39 & 1.97 & 1.32 & 0.86 \\
\hline & (0.64) & (1.69) & (0.29) & (0.29) \\
\hline \multirow[t]{2}{*}{ October } & 1.54 & 1.58 & 1.28 & 0.77 \\
\hline & $(0.42)$ & $(0.57)$ & $(0.58)$ & $(0.27)$ \\
\hline \multirow[t]{2}{*}{ November } & 1.80 & 1.51 & 0.83 & 0.60 \\
\hline & (1.01) & $(0.33)$ & $(0.24)$ & $(0.11)$ \\
\hline \multirow[t]{2}{*}{ December } & 1.61 & 1.61 & 0.74 & 0.57 \\
\hline & $(0.34)$ & $(0.33)$ & $(0.36)$ & (0.11) \\
\hline
\end{tabular}


Appendix B1. Average particle properties $( \pm S D)$ for all experiments recorded in the outflow of M. galloprovincialis, P. canaliculus and the control chambers.

\begin{tabular}{|c|c|c|c|}
\hline Species & M. galloprovincialis & P. canaliculus & Control \\
\hline Particles per $\mathrm{ml}$ & $\begin{array}{l}11131.72 \\
(8569.50)\end{array}$ & $\begin{array}{l}10050.68 \\
(7752.71)\end{array}$ & $\begin{array}{c}14829.77 \\
(11920.27)\end{array}$ \\
\hline Aspect Ratio & $\begin{array}{c}0.54 \\
(0.02)\end{array}$ & $\begin{array}{c}0.54 \\
(0.03)\end{array}$ & $\begin{array}{c}0.54 \\
(0.02)\end{array}$ \\
\hline Circle Fit & $\begin{array}{c}0.58 \\
(0.04)\end{array}$ & $\begin{array}{c}0.58 \\
(0.05)\end{array}$ & $\begin{array}{c}0.58 \\
(0.04)\end{array}$ \\
\hline Compactness & $\begin{array}{c}2.74 \\
(0.26)\end{array}$ & $\begin{array}{c}2.76 \\
(0.30)\end{array}$ & $\begin{array}{c}2.73 \\
(0.25)\end{array}$ \\
\hline Diameter (ESD) & $\begin{array}{c}4.44 \\
(0.55)\end{array}$ & $\begin{array}{c}4.42 \\
(0.63)\end{array}$ & $\begin{array}{c}4.44 \\
(0.57)\end{array}$ \\
\hline Edge Gradient & $\begin{array}{c}91.08 \\
(10.78)\end{array}$ & $\begin{array}{c}90.25 \\
(11.56)\end{array}$ & $\begin{array}{c}91.27 \\
(10.23)\end{array}$ \\
\hline Elongation & $\begin{array}{c}6.33 \\
(0.86)\end{array}$ & $\begin{array}{c}6.40 \\
(0.99)\end{array}$ & $\begin{array}{c}6.30 \\
(0.83)\end{array}$ \\
\hline Intensity & $\begin{array}{l}126.72 \\
(3.33)\end{array}$ & $\begin{array}{c}127.23 \\
(3.47)\end{array}$ & $\begin{array}{c}126.51 \\
(3.02)\end{array}$ \\
\hline Length & $\begin{array}{c}5.61 \\
(0.71)\end{array}$ & $\begin{array}{c}5.59 \\
(0.80)\end{array}$ & $\begin{array}{c}5.61 \\
(0.73)\end{array}$ \\
\hline Perimeter & $\begin{array}{l}22.80 \\
(3.24)\end{array}$ & $\begin{array}{l}22.59 \\
(3.63)\end{array}$ & $\begin{array}{l}22.79 \\
(3.15)\end{array}$ \\
\hline Roughness & $\begin{array}{c}1.26 \\
(0.03)\end{array}$ & $\begin{array}{c}1.26 \\
(0.04)\end{array}$ & $\begin{array}{c}1.26 \\
(0.03)\end{array}$ \\
\hline Volume (ESD) & $\begin{array}{c}188.03 \\
(286.67)\end{array}$ & $\begin{array}{l}142.45 \\
(81.86)\end{array}$ & $\begin{array}{l}149.79 \\
(55.36)\end{array}$ \\
\hline Width & $\begin{array}{c}2.91 \\
(0.35)\end{array}$ & $\begin{array}{c}2.88 \\
(0.41)\end{array}$ & $\begin{array}{c}2.92 \\
(0.34)\end{array}$ \\
\hline Between 2-5 & $\begin{array}{c}320.42 \\
(269.74)\end{array}$ & $\begin{array}{c}289.77 \\
(241.52)\end{array}$ & $\begin{array}{c}434.80 \\
(390.10)\end{array}$ \\
\hline Between 5-20 & $\begin{array}{c}115.17 \\
(101.05)\end{array}$ & $\begin{array}{l}102.83 \\
(93.88)\end{array}$ & $\begin{array}{c}144.92 \\
(123.84)\end{array}$ \\
\hline$>20$ & $\begin{array}{c}1.47 \\
(1.52)\end{array}$ & $\begin{array}{c}1.26 \\
(1.49)\end{array}$ & $\begin{array}{c}1.68 \\
(1.03)\end{array}$ \\
\hline
\end{tabular}


Appendix B2. Description of the particle properties used in this study. Descriptions are from the FlowCAM manual (FlowCAM Manual, 2011)

\begin{tabular}{|c|c|}
\hline $\begin{array}{l}\text { Particle } \\
\text { property }\end{array}$ & Description \\
\hline Aspect Ratio & $\begin{array}{l}\text { Width / length. (real }[0,1] ; 1 \text { is the value for a perfect circle; values } \\
\text { nearer zero are for particles long and thin) }\end{array}$ \\
\hline Circle Fit & $\begin{array}{l}\text { Deviation of the particle edge from a best-fit circle, normalised to the } \\
\text { range }(0,1) \text { where a perfect fit has the value of } 1 \text {. (real }[0,1] \text { ]; } 1 \text { is the } \\
\text { value for a perfect circle; values nearer zero are for particles that are } \\
\text { not at all circular) }\end{array}$ \\
\hline Compactness & $\begin{array}{l}\text { A shape parameter derived from the perimeter and the area. The } \\
\text { more convoluted the shape, the greater the value. A filled circle } \\
\text { should have the value of } 1.0 \text {. }\end{array}$ \\
\hline Diameter (ESD) & The Mean value of 36 feret measurements. (real>0) \\
\hline Edge Gradient & $\begin{array}{l}\text { Average intensity of the pixels making up the outside border of a } \\
\text { particle after a Sobel Edge Detect convolution filter has been applied } \\
\text { to the raw camera image. (real }[0,255])\end{array}$ \\
\hline Elongation & $\begin{array}{l}\text { A length/ breadth ratio based on Perimeter and Area with the } \\
\text { assumption that Area= length } \mathrm{x} \text { breadth and Perimeter=2(length+ } \\
\text { breadth). (real }>1 ; 1 \text { is the value for a filled circle or square; larger } \\
\text { values are for elongated particles) }\end{array}$ \\
\hline Intensity & $\begin{array}{l}\text { The average grayscale of the pixels making up a particle (grayscale } \\
\text { sum / number of pixels making up the particle). (real }[0,255] ; 255 \text { is } \\
\text { most intense) }\end{array}$ \\
\hline Length & The maximum value of 36 feret measurements. (real $>0$ ) \\
\hline Perimeter & $\begin{array}{l}\text { Total length of the edges making up particle including the edges of } \\
\text { any holes. (real >0) }\end{array}$ \\
\hline Roughness & $\begin{array}{l}\text { A measure of the unevenness or irregularity of a particle's surface-the } \\
\text { ratio of perimeter to convex perimeter. (real> } 1 ; 1 \text { is the value for a } \\
\text { filled shape with convex perimeter; larger values are for particles that } \\
\text { have interior holes and/or a non-convex perimeter) }\end{array}$ \\
\hline Volume (ESD) & Sphere volume calculated from ESD Diameter. (real > 0) \\
\hline Width & The minimum value of 36 feret measurements. (real >0) \\
\hline
\end{tabular}


Appendix B3. Average particle properties $( \pm S D)$ for all experiments recorded in the outflow of $M$. galloprovincialis, P. canaliculus and the control chambers.

\begin{tabular}{|c|c|c|c|}
\hline Species & M. galloprovincialis & P. canaliculus & Control \\
\hline \multirow[t]{2}{*}{ Circular particles } & 59.83 & 48.20 & 90.57 \\
\hline & (77.05) & (64.29) & $(111.47)$ \\
\hline \multirow[t]{2}{*}{ Small Circular } & 1689.90 & 1607.9 & 2410.78 \\
\hline & (1759.95) & (1591.00) & $(2409.88)$ \\
\hline \multirow[t]{2}{*}{ Short \& thick } & 1535.29 & 1341.78 & 2236.83 \\
\hline & (2133.76) & (1636.79) & (3461.31) \\
\hline \multirow[t]{2}{*}{ Long \& thin } & 115.20 & 96.92 & 148.21 \\
\hline & (146.96) & (77.47) & $(141.57)$ \\
\hline \multirow[t]{2}{*}{ Pennate Diatoms } & 26.19 & 23.55 & 42.60 \\
\hline & $(56.22)$ & (46.94) & (77.18) \\
\hline \multirow[t]{2}{*}{ Triangular } & 14.87 & 18.26 & 25.07 \\
\hline & (25.08) & (35.70) & $(30.30)$ \\
\hline \multirow{2}{*}{ Thecate dinoflagellates } & 8.28 & 7.30 & 18.17 \\
\hline & $(20.96)$ & $(20.32)$ & $(30.90)$ \\
\hline \multirow[t]{2}{*}{ Species A } & 25.38 & 24.34 & 35.10 \\
\hline & (63.13) & (63.27) & (75.37) \\
\hline \multirow[t]{2}{*}{ Species B } & 26.93 & 29.45 & 39.83 \\
\hline & $(46.83)$ & $(64.75)$ & $(63.60)$ \\
\hline \multirow[t]{2}{*}{ Species C } & 13.16 & 8.17 & 17.48 \\
\hline & $(30.56)$ & $(20.01)$ & $(23.67)$ \\
\hline \multirow[t]{2}{*}{ Clear Pennate Diatoms } & 9.09 & 8.76 & 13.17 \\
\hline & $(21.83)$ & $(21.33)$ & $(15.97)$ \\
\hline \multirow[t]{2}{*}{ Ciliates } & 0.42 & 0.00 & 1.68 \\
\hline & $(3.21)$ & $(0.00)$ & (3.37) \\
\hline \multirow[t]{2}{*}{ Skeletonema sp. } & 383.52 & 379.82 & 537.02 \\
\hline & $(742.51)$ & (771.29) & (969.01) \\
\hline \multirow[t]{2}{*}{ Tetraselmis sp. } & 9.30 & 10.88 & 12.68 \\
\hline & $(24.20)$ & $(26.71)$ & $(22.62)$ \\
\hline \multirow[t]{2}{*}{ Chaetoceros muelleri } & 251.27 & 164.18 & 291.58 \\
\hline & $(534.46)$ & (336.09) & $(507.47)$ \\
\hline \multirow[t]{2}{*}{ Chaetoceros calcitran } & 8.23 & 2.57 & 11.48 \\
\hline & (30.54) & (9.03) & $(24.42)$ \\
\hline \multirow[t]{2}{*}{ Isochrysis sp. } & 1.48 & 3.24 & 2.12 \\
\hline & $(6.84)$ & (13.23) & $(7.54)$ \\
\hline \multirow[t]{2}{*}{ Detritus } & 2493.19 & 2320.48 & 3103.94 \\
\hline & (1434.88) & (1489.47) & (1652.99) \\
\hline Inorganic particles & 135.03 & 105.14 & 187.49 \\
\hline
\end{tabular}




\begin{tabular}{cccc} 
& $(95.34)$ & $(83.87)$ & $(134.87)$ \\
2-5um unidentified & 3772.08 & 3229.68 & 7065.13 \\
& $(3457.01)$ & $(3099.69)$ & $(11978.66)$ \\
\multirow{2}{*}{$5-50$ um unidentified } & 594.58 & 473.61 & 682.63 \\
& $(823.99)$ & $(688.50)$ & $(853.96)$ \\
\hline \hline
\end{tabular}

Appendix B4. Particle types with images recorded in the FlowCAM library, table does not include 2 - $5 \mu \mathrm{m}$ ESD unidentifiable particles or $>5 \mu \mathrm{m}$ ESD unidentifiable particles.

\begin{tabular}{|c|c|c|}
\hline Particle Types & FlowCAM library Images & \\
\hline \multicolumn{3}{|l|}{ Circular particles } \\
\hline \multicolumn{3}{|l|}{$>5 \mu \mathrm{m}$ ESD } \\
\hline \multicolumn{3}{|l|}{ Small Circular } \\
\hline \multicolumn{3}{|l|}{$2-5 \mu \mathrm{m}$ ESD } \\
\hline \multicolumn{3}{|l|}{ Short \& thick } \\
\hline \multicolumn{3}{|l|}{ Long \& thin } \\
\hline \multicolumn{3}{|l|}{ Pennate Diatoms } \\
\hline \multicolumn{3}{|l|}{ Triangular } \\
\hline \multicolumn{3}{|c|}{ Thecate dinoflagellates } \\
\hline \multicolumn{3}{|l|}{ Species A } \\
\hline \multicolumn{3}{|l|}{ Species B } \\
\hline \multicolumn{3}{|l|}{ Species C } \\
\hline \multicolumn{3}{|c|}{ Clear Pennate Diatoms } \\
\hline Ciliates & & \\
\hline
\end{tabular}


Skeletonema sp.

Tetraselmis sp.

Chaetoceros muelleri

Chaetoceros calcitrans

Isochysis sp.

Detritus

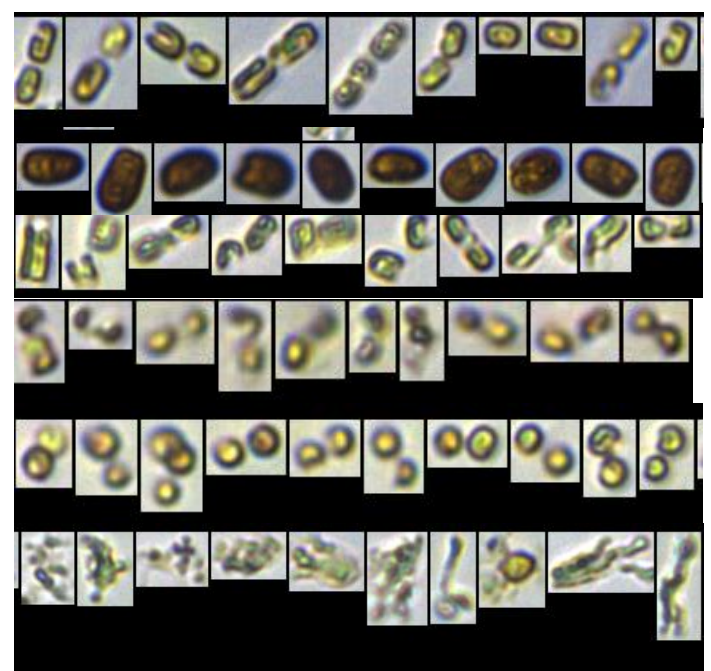

Inorganic particles

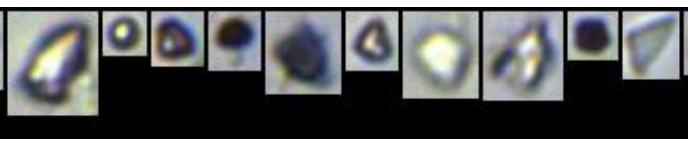

